Claremont Colleges

Scholarship@ Claremont

CGU Theses \& Dissertations

CGU Student Scholarship

2019

\title{
Memories of the Teacher: A Reflection of Enduring Ideals
}

Katherine Cooke

Claremont Graduate University

\section{Recommended Citation}

Cooke, Katherine. (2019). Memories of the Teacher: A Reflection of Enduring Ideals. CGU Theses \& Dissertations, 140. https://scholarship.claremont.edu/cgu_etd/140.

This Open Access Master's Thesis is brought to you for free and open access by the CGU Student Scholarship at Scholarship @ Claremont. It has been accepted for inclusion in CGU Theses \& Dissertations by an authorized administrator of Scholarship @ Claremont. For more information, please contact scholarship@cuc.claremont.edu. 
Memories of the Teacher: A Reflection of Enduring Ideals

Katherine E. Cooke

Claremont Graduate University 


\section{Table of Contents}

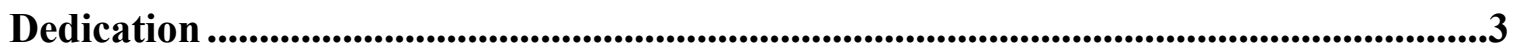

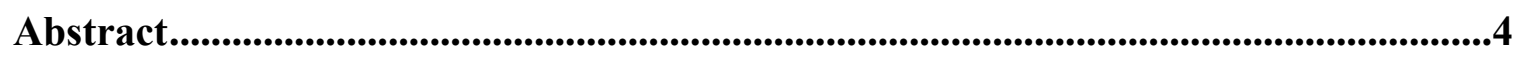

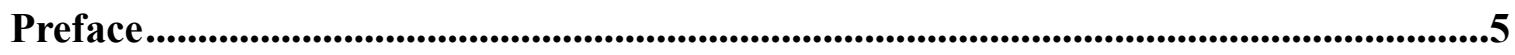

Part A: Who am I and Why do I Want to be a Teacher? ....................................................6

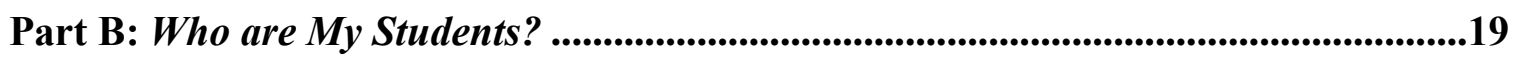

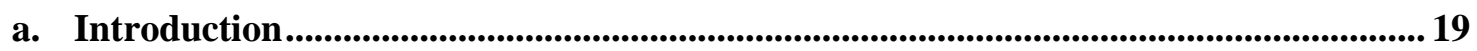

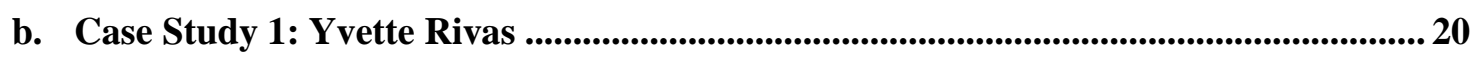

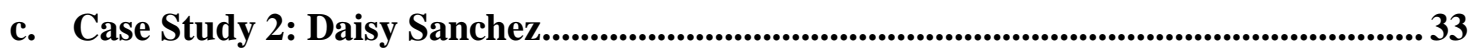

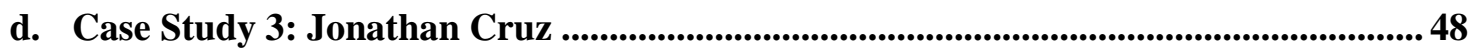

e. Concluding Thoughts on Case Studies...................................................................65

Part C: What is Happening in my Community, School, and Classroom? .....................65

Part D: Analysis of Teacher Effectiveness.........................................................................89

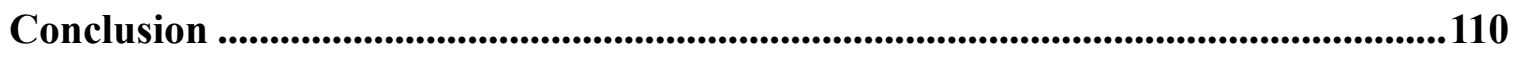

References......................................................................................................................................112

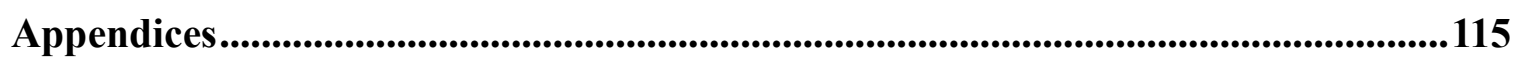




\section{Dedication}

This ethnography is dedicated to the members of my English cohort and my Faculty Advisor, Keisha Goosby, for sharing in and sympathizing with the work experience in this first year of teaching; to my family, for loving and supporting me unconditionally; and most of all to the teachers I've had, past and present, who have encouraged me throughout my life and engendered in me the everlasting desire to learn. 


\begin{abstract}
In order to educate my students in my first year of teaching, I embarked upon a research project that would allow me to get to know their strengths and needs in addition to identifying my own possible biases and pre-conceived educational ideas. My research spreads from my own life to the lives of three focus students from various populations: one English learner, one student who receives special education services, and one student who has had significant life experiences that might contribute to his academic work. I interviewed all three students and their families to develop an action plan to help support their work this year. In an effort to better understand their lives, I also researched the school itself and the surrounding city by interviewing community members and referencing statistics online. Ultimately with all of this information I was able to create an action plan for each student using educational strategies from various sources that supported their academic growth this year.
\end{abstract}

Keywords: Effectiveness, Assets, Needs, Education 


\section{Preface}

This ethnographic narrative is in part the story of my journey throughout my first year of teaching, but is mainly the collected story of three of my students, their families, and their community. I began this journey by looking carefully at my own experience with education and how it has shaped my thoughts and opinions on the subject. In gathering data about my three focus students, one an English learner, one a student receiving special education services, and one a student with significant life experiences, I was able to formulate an action plan for each one. I interviewed the students and their families, their past teachers, and examined data from their previous year of schooling in order to compile information on each of these students. In order to track their progress throughout the year, I collected student work samples and continually evaluated them based on the goals I'd set out at the beginning of the year. To ensure I was able to understand my students as much as possible, I also interviewed various community members and school staff. I gathered a description of the area and the school that was as free from bias as possible, wanting to work with what is actually present, and not any judgement I might subconsciously place upon what I was studying. The largest challenges I faced throughout the course of this research were the somewhat isolated nature of the area (finding community members willing to be interviewed proved difficult), and my own anxiety over intruding on the lives of others (which I discuss more later in Part B). Ultimately, my wish for this work was that it would aid me in my first year of teaching, allowing me to be a better teacher to more of my students than I might otherwise have been. I believe this goal was met as a result of all my research. 


\section{Part A: Who Am I and Why Do I Want to be a Teacher?}

\section{Personal Experiences and Beliefs}

My $11^{\text {th }}$ grade English class was one of the most profound experiences of my life, and I will be dedicating this essay and my career as a teacher to the memory of the teacher of that class, Lynette Creasy. While many ethnographic papers may begin with a detailing of one's family, or an overview of the role education has performed throughout one's life, I can think of no better way to begin my own than with that junior year class. At the end of $10^{\text {th }}$ grade, it was decided that I should be allowed into the AP Language class for $11^{\text {th }}$ grade if I so chose. Because I have always been the kind of student to leap at opportunities for challenge, the decision to say yes should have been an easy one. However, I had heard things about the class and its teacher from other students. To say the "reviews" were a mixed bag is an understatement. It was described as an experience that would "either make or break" a student, a teacher so tough, so demanding, that failure was not a distance possibility, but in fact a very real probability.

The class had been AP American Literature, and Ms. Creasy refused to alter her curriculum to ensure the passing of the AP Language exam for her students. It is testament to her formidable determination, reputation, and wit, and the fact that it was a private school, that she was allowed to do this without any real pushback. As a disclaimer, this decision, and many others made by the infamous Lynette Creasy, is not necessarily one that I myself would make as a teacher. While most of her class performed exceptionally well on the AP exam, I believe the addition of even a minor amount of content taught to the AP standard could have lowered anxiety surrounding the entire affair. At the same time, I do understand why she made this decision; she wanted her class to be about the admiration and study of literature, a time to deepen understanding and engage in philosophical debate with peers, not a chunk of time allotted for the 
memorization and subsequent regurgitation of facts and opinions that held no real meaning for or connection to anyone in the class. For many reasons, Ms. Creasy was not a perfect teacher; I would say she didn't even come close to achieving that. There are few rubrics for studying her method that would add up to her being technically good. What she was, however, was a great teacher in ways difficult to measure but I believe in some ways more important.

Though I had heard the horror stories, the students who cried their way through assignments for the class, I found my courage and enrolled. I was determined to succeed and sure that I would be the type of student who was able to mesh with Creasy's teaching style. This was one of Ms. Creasy's main faults as a teacher: she only had one way of teaching, and that was the tough love way. If you did not perform to her expectations, she would not bend to make you more successful. You either learned the way she wanted you to, or you failed her class. This is ultimately not a fair way of teaching. As Howard Gardner hypothesized, there are "multiple intelligences," meaning students learn in different ways. In studying this phenomenon in her paper "Multiple Intelligences in the Classroom: A Fresh Look at Teaching Writing," Melody Lunenburg goes on to say “...these differences challenge an educational system that assumes everyone can learn the same subject matter in the same way and that a uniform measure can be used to test student learning” (2014,pg. 1). While Ms. Creasy encouraged students to express their understanding in many different ways (essays, oral presentations, artistic renderings, etc.), she did not relay information in many different ways, and she almost never reminded the class of prior knowledge; either the student remembered it on his/her own, or he/she would fail. Fortunately, I was correct in my suspicion that this way of learning would suit me. I responded very well to Ms. Creasy's style, earning an A- on my first essay when the average grade was a C. I did not always perform so well, but I can confidently say that I never dropped below average in 
the class. Turning in that first essay was a lesson in fear; I vividly remember shaking as I placed it in the box, terrified of the outcome despite having worked harder on it than I'd ever worked on anything in my life. That was something Ms. Creasy did well: students virtually never slacked off for her class. For students who had not performed as well on the first essay, Creasy showed a rare moment of kindness: they could rewrite for a better grade. Rewrites, I found in my undergraduate days, have always taught me more than just getting a grade on a paper and promptly forgetting about it. The Teaching Center at Washington University in St. Louis recommends rewrites if expectations are laid out clearly: "If you want students to improve their writing, give them an opportunity to apply what they have learned from your comments to a new, revised draft" (The Teaching Center Washington University St. Louis, 2018). Everyone eligible took Ms. Creasy up on the opportunity, and the class as a whole settled into a better place mentally and intellectually. While that was the only time she showed mercy, it did assist in solidifying a more productive, slightly less fearful classroom environment that would enable the creation of some truly spectacular literary observations.

Chief among these was the "Billy Budd Project." Rather than read Moby Dick, Ms. Creasy insisted her students focus on one of Melville's shorter works, "Billy Budd." At only 91 pages, the book was one that could be more easily reread and analyzed as a whole, rather than being forced to focus on only pieces of it. The project had such a reputation that almost everyone at the high school knew what it was: analyze "Billy Budd" and develop a thesis with three other people and then present it along with supporting evidence to the rest of the class as a 50-minute lecture. Visual aids were encouraged but not necessary. To give a sense of the scope of the project: we had two months to complete it, my group visited the local library in addition to the school library no fewer than 12 times, our outline was 23 pages, and we had over 60 sources in 
our bibliography. Today, what I remember most from this project was a sense of awe over how many different perspectives and ideas could come from a single 90-page book. How many years had this project been assigned, how many groups per year, and almost never was there a repeated idea. Even if the basic concepts were similar, the way they were presented and supported would be different. "How incredible," I remember thinking, "that such a small piece of literature can contain such a vast treasure trove of ideas."

And this, ultimately, is what I took from Lynette Creasy's class. Through all the essays and readings, lectures and quizzes, I never once learned from her what to think. Ms. Creasy was of the mind that so long as it could be supported with textual evidence, the opinion was valid. While she would dock points if your essay was ill-structured or under-supported, she never once to my knowledge gave a bad grade simply because the student had a different opinion than she did. And thus, she only ever taught me how to think. I owe her my ability to keep an open mind about what I'm reading or learning. Because of her I understand that not only do different opinions of the same material exist, but that none of them are inherently incorrect so long as the text can support them. Simply because it is not how you viewed the novel, does not mean it is wrong. Literature has the profound ability to open our minds, to make us grow and change and learn. If we give it the opportunity, it can teach us about other cultures, other worlds and concepts that we've never thought about. Literature is immensely powerful, and in looking back at Creasy's class, I realize that this is not the only thing I learned. I also learned that in order for literature to exert its power to the fullest, to facilitate the expansion of the mind, the acceptance of "otherness," and the growth of the self, it requires the support of a teacher who recognizes that power and attempts to act as a conduit for it, not limiting the students' exposure to it, but gently organizing how it is presented to them to ease them into understanding. 


\section{My Assets and Needs}

With my reflection regarding that class and the impact its teacher had on me, I have realized that that style of teaching is one that I'd been exposed to already for most of my life. To be clear, I had not had a teacher demand that level of excellence before, but I had absolutely experienced the approach of teaching not the what but the how of thinking. Both of my parents were teachers when I was growing up. My father taught AP US history, and my mother taught horseback riding lessons. My father and mother both have always believed in allowing my sister and myself to think for ourselves. Growing up, they would provide us with necessary information and attempt to at least somewhat guide us to the conclusion they believed in, but they never insisted on our doing something simply because they said to. For example, they would tell us that we should put on sunscreen before spending time outside, as we may get sunburned without it, but ultimately it was our decision, and we were responsible for the consequences of our action or inaction. This is a metaphor for their style of teaching in pretty much every area. They provided their students with the necessary information for success, gave them clear expectations for the outcome, but ultimately allowed them to utilize their own intellect to approach things. Rather than putting on sunscreen, for example, a student might instead wear a hat and long sleeves. My parents as teachers would not punish the student for this: the ultimate outcome was still that the student was not burned. The method of achieving the end goal was always something my parents believed should not be dictated.

As a more school-related example, a student could be told that they must read a certain book and write an essay about it, but they would not be told exactly what the essay must contain in terms of ideas. That portion of the assignment would be their choice, and so long as the essay was well-written and the idea supported, the student was deemed successful. This approach to 
teaching is the practice of encouraging critical thinking in students. In an article called "All Our Students Thinking," included in Educational Leadership, by Nel Noddings, she relates a story of a teenaged student required to memorize facts for a history test. She goes on to say: "When I talked with her, however, it was clear that she had not been asked to think and would soon forget the memorized facts. None of it meant anything to her; passing the test was her only objective" (2008, pgs. 8-13). Noddings highlights the problem with not engaging critical thinking in students: information that is not connected to anything other than the need to pass a test is difficult, if not impossible, for students to retain.

Based on his propensity for insisting students engage in critical thinking, it is little wonder that my father got a job at a small private school outside of St. Paul, Minnesota that emphasized teaching students how to think and problem solve, not just teach them a set-in-stone list of facts. Because my father taught there, I was able to attend the school through a tuition remission program. I am still incredibly grateful for this opportunity, because from kindergarten through $8^{\text {th }}$ grade, I was taught in a way that did not stifle my creativity or insist that everyone think about everything the same way.

The flip side of this coin has of course also impacted my view of teaching and learning. I have struggled most in school when expectations are unclear or only some answers are acceptable. First and foremost a hindrance to my performing well in school has been lack of clear expectations. I have always found it helpful when teachers employed rubrics. I like to know what I should be giving a teacher in my work for it to be counted successful. I've always been frustrated when a teacher has lectured on huge amounts of material but given no indication as to what is essential and will be tested, and what is not. 
Some history classes in particular have made this difficult for me. At times tests would cover main ideas learned throughout the course of five or so chapters, ensuring we knew the critical events of that time period, but there were other assessments that then would test knowledge of miniscule details over a different five chapters. As a result, I felt as though I never knew what I was expected to know, what was important, versus just interesting information given for the sake of enjoying the class. Clearer expectations and ways to demonstrate my understanding other than a timed test would have benefitted me greatly. Timed assessments have always made me extraordinarily anxious, to the point where my mind would be blank for the first 15 minutes as I tried to calm myself down to the point of being able to remember at least some of what I'd learned. I believe if there had been less time pressure and greater transparency regarding necessary knowledge, I would have performed better on tests, retained more information for longer, and enjoyed the subject matter more. Douglas Fisher and Nancy Frey emphasize the need for introducing purpose into the classroom in their book The Purposeful Classroom. They state, "An established purpose alerts learners to important information and garners their attention while helping teachers decide how best to use their instructional time" (2011, pg. 2). With clearer purpose employed in every class, I feel I would have been able to more easily learn the necessary material, and it would have led to a less stressful, more joyful experience for me. History classes, unfortunately, were not the only ones that fell prey to lack of clear purpose or not allowing for critical thinking.

Expecting specific answers is a fault of some English classes I've had more than any other subject. In my opinion, essays should be largely open topic, with emphasis placed on thoughtful analysis and support of whatever opinion the student might have on the text, so long as those expectations are grade appropriate. My favorite English classes always operated this 
way. I did encounter some, however, that seemed to employ a secret necessary opinion on texts. An essay for example should support the teacher's opinion, even if the students were not made aware of that opinion. There was no room for disagreement, even if the student was successful in using textual evidence and analysis to support their claim. This type of English teacher was always particularly frustrating to me because the class then combined lack of freedom with lack of clear expectation. Essays became guessing games, trying to figure out what the teacher wanted to hear, rather than an opportunity for exploration and growth through identifying one's own beliefs and supporting them through the use of the text.

\section{Choice to Be an Educator}

My experiences in learning, both positive and negative, and my family background have combined to both influence my educational philosophy and also solidify my choice to be an educator. Most broadly, my parents have both been educators for my entire life, and my grandparents on my father's side were teachers as well, so sheer exposure to the profession has had a significant influence on my decision to pursue teaching as a career. I've had an inside view of a sort to the life of an educator. I've seen its challenges and its triumphs. What has always been clearest to me is that no matter how difficult the imparting of knowledge becomes, the obstacles that are encountered, there is still such an intense feeling of joy when a student finally understands something and succeeds. I want that feeling, even if it doesn't happen every day, regardless of how much hardship must be endured in the meantime. I've already experienced that feeling a little bit in my work tutoring, my work as a volunteer with The Miracle Project helping children with developmental disabilities create and perform a musical, and my work as a coteacher for a summer theater program with lower and middle school aged children. To a slightly lesser extent, I even experienced that fierce joy during my time at the Strand Bookstore, helping 
children and young adults of all ages find literature that would speak to them. There is a connection that happens when student, teacher, and material being taught are all suddenly in alignment that is nearly impossible to describe. It's a victory for all parties involved, something that can only be accomplished through absolute cooperation and open-mindedness.

In all my experiences teaching before, I've found that I communicate best through guidance based on questions. "How did you come to this conclusion?" "Why do you want to have this character behave this way?" "How can you help this play come to life?" "Why did you like that book more than any other?" These are all things that have helped me gain a better understanding of my students and where they're coming from, and what information they may already have or how they've understood (or not understood) what I've already attempted to teach them. Based on their answers, I can then offer some guidance that could help them dig deeper into their understanding.

As a teacher I want to take the best of what my former teachers had to offer and attempt to avoid the pitfalls they might have experienced. From my elementary education and my time as Ms. Creasy's student, I want to take the notion of teaching my students how to think rather than what to think. I want to encourage them to open their minds to possibilities inherent in literature, I want to show them why it is such a powerful force, and hopefully they will develop a love for it like I did because of this. I want to have high expectations for my students that are always clearly laid out. On the other side of what I want my classroom to be is what I don't want it to be. I never want my students to be afraid of sharing their ideas because they believe they aren't the same ideas I have. I never want my students to have to guess what they need to do in order to succeed. And while I want to have high expectations for my students, I want those expectations to be reasonable. Everyone in my classroom will have the opportunity to succeed and will be 
given the tools to help ensure that happens. I want my students to feel comfortable asking questions if they don't understand something, and I want to make sure I remind them of things that they've already learned that may help them.

The positive experiences I've had in classrooms like Ms. Creasy's are what pushed me to choosing this as a career. It's always been at the back of my mind that I've enjoyed my teaching experiences, but it was thinking about my time as a student that really solidified my decision. I want to be the kind of teacher that I would have loved to have had when I was a student. I want to be the teacher who shows at least some students how incredible literature can be, who gives them a love for expressing themselves whether that is in writing, oral presentation, or some other medium that can be explored through my assignments. I want to teach to all students, not just ones that think the same way I do. I will teach my students in a variety of different ways using art and technology, drawing connections to science, history, and even math to help round out their access to literature in addition to giving them the opportunity to express their knowledge in a multitude of ways. Part of teaching I feel is also inherently learning. Teachers should be open to learning from their students over the course of the day. It's entirely possible that as an English teacher I will have a student who looks at a novel in a way I had never considered. I never want to punish that kind of creativity; I want to celebrate it and learn from it.

\section{Hopes, Dreams, \& Fears}

The previous few paragraphs largely encompass my hopes, and dreams, but I will outline a couple more in addition to some of my fears. In my first year of teaching, my most attainable hope and dream is that I reach even one student. If I can change even one student's life or perspective of literature in my first year, I will be ecstatic. Better than that, of course, would be reaching a number of students that way. As a first-year teacher though, I expect to encounter 
difficulties. Being a really good, successful teacher takes experience in addition to heart and knowledge. At the end of my master's degree at Claremont Graduate University, I expect that I will have plenty of knowledge. I've always possessed a tremendous amount of heart, refusing to give up, always working toward something better and trying new avenues if the ones I have used have failed. I will be on my way to having some experience after doing my summer pre-teaching, but ultimately, the experience portion will just have to come with time in the classroom. It will be a learning experience for both my students and me.

This, actually, relates heavily to my fear. My greatest fear in being a teacher is the vast amount of responsibility. While I think I'm ready for it, that I can handle it, as I've always been organized and responsible in other areas of life, I also recognize how crucial my role will be. I still remember great teachers I've had, and I still remember ones that I didn't like, that I felt I learned nothing from or the ones that actively increased my dislike for a subject. I'm terrified of failing my students. I am responsible for their acquisition of knowledge for a full year in English class, and failure on my part makes school more difficult for them down the road. If I give them a bad experience in that one year, they may decide they hate English for the rest of their school careers and beyond. This might seem dramatic, and perhaps it is a bit, but my $7^{\text {th }}$ grade math teacher convinced me that I hated math and was terrible at it until I took calculus in $12^{\text {th }}$ grade and was not only good at it, but also enjoyed it. For five years I detested math just because of that one teacher. Teachers have a huge impact on the lives of their students and how they approach learning. I think it's important that I remember that, and so I'm glad that it's a genuine fear I have. It will keep me humble and ensure that I remember that being a teacher is not about power or self-gain, but about the students and facilitating their growth. I will overcome this roadblock by using what I'm learning at CGU now, employing the strategies I'm collecting for 
creating a productive classroom environment, and overall just planning. If I stay on top of what I'm supposed to be doing, what my students need to learn, and how to help them learn those things, it will lead to overall success in my first year.

That being said, there are a couple more immediate and concrete potential roadblocks for me as a teacher. The first of which is perhaps a bit silly but is something I've thought about as having the potential for being a problem. I look very young, and as such, my students might not view me as an authority figure the way they would view someone who was clearly older than they. I've thought of a couple ways of overcoming this, the first of which is simply to dress professionally. I will look older if I am not wearing jeans and a t-shirt like they are. The second method for overcoming this obstacle is more involved. From the first day of class, I have to establish my authority. I must strike the balance described by Marzano in $\underline{\text { Classroom }}$ Management that Works. Marzano states, "Without the foundation of a good relationship, students commonly resist rules and procedures...” (2003, pg. 41). I won't be mean or overly stern, but I will set clear behavioral expectations for my class.

The second roadblock I've considered is the fact that I personally have never attended public school. Because my father was an educator, I was able to attend private schools for little or no money so my family could afford it. I recognize how privileged I was in that way, the increased opportunities I had as a result, and that may be something that comes between my students and me. I will handle this gap in my understanding in the only way I know how: by listening to my students. I have always tried to have compassion for everyone I meet, regardless of who they are or where they come from. I will apply this same compassion to my students. Whatever their experiences are, their truths, I will listen without judgment and attempt to offer support in whatever ways they need. I will search for ways to give them similar opportunities to 
the ones I was lucky enough to receive. A person's background shouldn't determine what they can achieve in life, especially when that background is something as uncontrollable as where you're from and to whom you were born.

\section{Social Justice}

Addressing the topic of social justice further, I'd like to use my experiences to try and give people who aren't as lucky the same kind of opportunities. I hold with what John Dewey states in his "My Pedagogic Creed," that "I believe that education is the fundamental method of social progress and reform." I believe that we all have a duty to pay forward any good we receive in our life, even if it is just in the form of knowledge. As I've already said, I want all of my students to succeed in my class, regardless of who they are, where they're from, or how they learn. This I think is the core of social justice: that we are all equal and we all have a responsibility to ensure equal opportunity is given to those around us, particularly as teachers. My lesson plans will allow for many ways of learning and expressing mastery of material, and my curriculum will include texts written from as many perspectives as possible so that all students may feel represented. Lynette Creasy attempted to accomplish this, having us read Beloved and a few other similar novels, but I feel as though she didn't go far enough. There are so many under-taught great works of literature written by minorities, and I would like to include them in my classroom. Finally, I want to use my performing arts experience to offer acting classes and maybe even the formation of a theater company. I would do this as a volunteer, outside of scheduled, paid classroom time. While this may not reach every student in the school, I think it could give some of them a new avenue of expression, which can be invaluable to growth as a person. 
Lynette Creasy was a once-in-a-lifetime teacher for me. I have never encountered a teacher who moved me so profoundly or taught me so much outside the scope of the classroom. Every time I consider my future as a teacher, I am reminded of her: her strengths, her weaknesses, her frustration, and her joy. She made mistakes, as all teachers do, and I am sure I will make mistakes over the course of my career as well. Overall, though, she embodied some of the qualities I most hope to have as a teacher. I want to invite my students to think about new things and in new ways in relation to literature every day that they're in my class. I want them to find characters they relate to and some who are utterly foreign and examine those ties in a way that furthers their personal growth. I want to give my students the information and support they need to succeed without stifling their ideas and creativity. Most of all, I want to always be working toward being the best teacher I can be, and my attendance at CGU and entrance into my first year of teaching mark the beginning of that journey.

\section{Student Research}

\section{Introduction}

After recognizing and evaluating my own cultural and educational background for the experiences and biases it gave me, it became clear that I should do the same for my students in order to gain a deeper understanding of them. As I could not realistically delve deeply into the lives of all 171 of my students over the course of a semester, I chose three focus students who would represent different educational groups in my classroom: first, an English learner; second, a student with an IEP/504 Plan or GATE status; and third, a student with some sort of significant life experience. All three of these students are $7^{\text {th }}$ graders at Adams Middle School in Blakesburg. I felt that gathering data about these students would give me a fairly broad sampling of who 
could be making up my general classroom. For each of these three students, I collected data about their educational and personal lives, and then created an action plan that will help them achieve their academic goals. To collect data, I interviewed the students, conducted a home visit and interviewed their families, spoke with former teachers if possible, and examined the work the students had done in my class, including assessments, both formative and summative. My hope is that in gaining a clear idea of these three students' assets and needs, I will be able to create lessons that are engaging, challenging, and address the needs of all of my students in order to lead them to academic and social success.

\section{Case Study 1: Yvette Rivas}

Demographic Information. On the first day of school at Adams Middle School in Blakesburg, $7^{\text {th }}$ grader Yvette Rivas speed-shuffled her way into the classroom. Head down, hair tied back in a low ponytail, but bangs still covering her eyes, she came to a lurching stop in front of me, stared up at my face in shock, and exclaimed "You're new!" I blinked back at her for a moment before recovering and giving her a smile. I replied that yes, I was new, and then I asked her name. She smiled back at me, told me her name, and asked if I was Miss Cookie (a mispronunciation of my name, though one I have experienced before). She followed her question with a low guffaw, though it was not a laugh that was aimed to hurt; rather, it was a laugh that invited those around her to join in. I gently corrected her and told her to take a seat. She gave me a small wave, glanced around the classroom quickly, and then shuffled her way to a seat at the side of the room, facing the door. She sat down with her backpack still on, shoved bangs out of her eyes, and pushed her school sweatshirt sleeves up to her elbows as if signaling to the world that she was ready to take on any challenge that might come her way. 
In the first few weeks of class, I got to know Yvette better and better, both as a student and also as a person. I discovered that she was an EL; her simple spoken English is fairly good; however, she struggles with the academic register and her basic convention skills are not up to the $7^{\text {th }}$ grade Common Core standard (she frequently makes grammatical errors). I also learned that she is something of a prankster; she enjoys playing light-hearted jokes on people, always then engaging other students with her guffawing. I chose Yvette for my focus student because I find her language challenges very interesting, and I also have found her to be a thoughtful, kind, fun-loving, and intelligent addition to my class. Inside the classroom, Yvette is something of an expert in adjusting her own learning experience. She is able to recognize if she needs to move to a new location in order to learn, and is also unafraid to ask for help. She frequently attends office hours to improve her work, and is consistently respectful both to myself and to the other students in the class. She is fantastic at engaging in discussions with her classmates, but does still sometimes need to interrupt her sentence with a "what's it called" and then a description rather than the standard word for something. She is well liked among her classmates and rarely complains when given work to do. She has an inquisitive mind and a determination that makes her a wonderful student. Outside the classroom she demonstrates her friendly personality with everyone she meets. At times she goes to see the school counselor because of a minor issue with a classmate, but it is rare, and Yvette always takes it upon herself to solve interpersonal problems before they reach a level that requires adult intervention. She is friendly with her family and according to her mother, is an accomplished amateur singer/dancer of $60 \mathrm{~s}$ and $80 \mathrm{~s}$ music.

While Yvette certainly displays many strengths both inside and outside of the classroom, she definitely still has room for growth. As was mentioned previously, her conversational English is fairly good, but she lacks greater academic vocabulary that would allow her to 
reclassify. This was evidenced first to me in her conversations with me, as she would be unable to produce some of what I would think of as middle-tier vocabulary words such as "poverty," "merchandise," and "hawk." She also struggled with academic vocabulary relating to English, words like "analysis," "evidence," and "central idea." She was by no means the only student who struggled with these vocabulary words, but it did seem to be one of the main barriers between her and her performing at her actual best. Her other growth area, also shared by many of the other students in the class, is in the conventions of written English. She struggles with correct plurals (e.g. "womens" instead of "women"), list making, and avoiding sentence fragments (see Figure A2), in addition to subject-verb agreement and general spelling issues (see Figure A1). Outside of academics, Yvette mainly has difficulty with personal space boundaries. She does not usually touch others, but she is almost always touching or taking items that do not belong to her. She does not do this maliciously (she is not trying to hide or steal anything from anyone) she simply will pick up anything that is in front of her or near her, regardless of whether or not it is hers. This can sometimes make other students feel uncomfortable, and occasionally will interfere with their learning (if she takes a pencil from them, for example). None of these growth areas presents an insurmountable task, particularly when all of Yvette's strengths are also taken into consideration. It will require work both on my part and on hers, but I do believe she will continue to improve in all of these areas.

Assets \& Needs: Academic Standing. Yvette is an English learner, and while the school does not use further designation (e.g.: emerging, expanding, bridging), due to her comfort with conversational English but difficulty with academic vocabulary, I believe her to be between expanding and bridging. She has a fairly firm grasp of English, but her academic language is not yet strong enough to reclassify. Cummins (1979) first discussed this phenomenon as being the 
difference between Basic Interpersonal Communicative Skills (BICS) and Cognitive Academic Language Proficiency (CALP) (p. 121-129). Cummins believes that while conversational English can be acquired in as little as two years of immersion, academic registers of English can take between five and seven years. While Yvette's conversational English is quite good, her academic English is not quite developed yet. On formative assessments, she usually does fairly well, earning mostly A's and B's as she is able to ask for help when items are unclear. She also performs better when the task is fairly short; after an extended period of time (15 minutes roughly) she struggles to focus and loses the ability to perform at her best, often turning to drawing in the margins of her work (see Figure A1). Summative assessments are therefore a struggle for her. On initial attempts, she typically earns in the $\mathrm{C}$ range, but is able to ask questions and re-write pieces during guided study in order to then earn a significantly improved grade. It seems that the help isn't even very necessary; what she truly needs is the time away from the writing to take a break before continuing. On standardized tests, Yvette struggles the most. On a recent benchmark test, she received a D; her RI score is "Below Basic;" and her iReady score is "two or more levels below." These tests do not offer the same scaffolds and differentiation that could be included on a formative or summative assessment, and that, combined with the length of such tests, results in Yvette scoring poorly.

Overall, Yvette works best in groups. Collaborative work aids in keeping her on task, I believe because she has automatic, easily accessible help should she become stumped by a part of the assigned work. Independent work is more difficult for her. Working independently, she becomes distracted or bored, or gives up on the work entirely, claiming it is too difficult. It is necessary to intervene before she abandons her work, because once she has chosen that path for the day, it is nearly impossible to get her back on task, regardless of how much guidance is 
given. She always enjoys discussion work and completes it easily. She also completes shorter written pieces, particularly when based around a visual (picture, video, etc.). She has greatest difficulty completing reading and longer writing assignments. If the reading does not include visual aspects and is longer than a page, she gets tired, believes it to be too difficult, and gives up if she is working alone. Yvette does usually complete tasks as directed, though she sometimes struggles to do so if she does not understand the instructions. Words in the directions must be kept simple and concise, the phrasing cannot be complex, and the directions need to be clearly laid out step-by-step. Overall, Yvette is extremely creative, and has fantastic communication skills outside of academics. Her critical thinking is average, slipping to the low end if she does not understand the task set for her. Her main growth area is in her academic communication.

Yvette's largest struggles are found in standards ELA.L.7.1 and ELA.RI.2 (conventions of language, and finding the central ideas in an informational text respectively). I believe she is struggling in the first area because of her grammar and spelling difficulties as mentioned earlier. With additional work on subject/verb agreement, plurals, complete sentence structure, and spelling, I believe Yvette will improve dramatically in this area. On the recent benchmark test, she answered all three conventions of language questions incorrectly, and I have seen in her work that she does not utilize standard grammar or spelling. As for the struggle with central ideas in informational text, I believe the main block to success in this area lies in Yvette's somewhat limited academic English vocabulary. If an article contains too many large or academic terms, Yvette is unable to comprehend the text as a whole and can even check out completely and stop getting any meaning from what she reads at all. On the benchmark test, she left one question relating to this RI standard blank and answered another three incorrectly. She was able to answer far more questions correctly for other standards, particularly the literature standards. Where 
Yvette truly excels is in the speaking and listening standards. She is able to clearly share her ideas, working around any gaps in her vocabulary and still communicating with others. She is very good at listening to the students around her and clarifying what they have to say, adding on using academic sentence frames, or contradicting their opinions in a way that furthers the discourse.

Assets \& Needs: Socio-Emotional Development \& Social Identity. Yvette brings joy to the students and teachers around her. She usually has a smile on her face; she loves laughing and is a connoisseur of pranks and jokes. She is also not afraid to be on the receiving end of similar pranks or jokes, which makes her all the more beloved by those around her. She has an enormous strength in her ability to make friends with anyone around her. Where she has room for growth is in her awareness of social boundaries. As mentioned previously, Yvette has the tendency to touch everything around her, even if it does not belong to her. Students around her sometimes get annoyed when she takes things from their desk without asking, leading to small verbal spats, which mostly end very quickly with Yvette backing off and apologizing. She doesn't notice she is doing it; it's simply a habit of hers that makes others uncomfortable. In class, one of the expectations is that students respect others by not touching what isn't theirs without permission. We have written and spoken about why that is an important expectation, and we have even rehearsed the polite way of asking to hold something that does not belong to us. All of these practices have helped Yvette learn to not reach outside her personal space, but it will take time and continual reminders before this new way of living (not touching what isn't hers) begins to really become a habit for her.

Students are asked each day to do a fair amount of independent work in class and are sometimes required to complete work outside of class by a certain due date. They are also 
expected to advocate for themselves if they believe they could learn better with some change (e.g. seating). All of these items encourage students, Yvette included, to self-manage and take ownership of their own education. Growth mindset is encouraged in the students' ability to redo assignments during guided study. During the designated time outside of class hours each week, students are able to fix mistakes and learn more about the lessons of the past week. As Carol Dweck clarifies (2015), “...students who believed their intelligence could be developed (a growth mindset) outperformed those who believed their intelligence was fixed (a fixed mindset)" (p. 20-24). It is important for all of my students to believe they can improve and become more intelligent because they will then perform better academically. Yvette's willingness to improve herself academically has resulted in a more positive outlook in class for her and an improved performance.

The development of and learning about social awareness and relationship skills occurs mainly during group work in class. The class has discussed what makes for a good discussion in terms of behavior; there are academic sentence frames displayed for student use; and students are aware that they may have to work with different partners, even perhaps classmates they do not know or with whom they are not friends. All of these are opportunities for Yvette to further her socio-emotional development.

Yvette is a self-proclaimed "tom-boy" who sees herself as "nice, sweet, and cool." She identifies as Hispanic, Spanish-speaking, and "has no time for boys." She is very much a part of the neighborhood where she both lives and goes to school; she knows the area, it's where she grew up. In creating an inclusive environment, I encourage the use of other languages to support the learning of English. If students don't know the word in English, they are welcome to say it in Spanish and then describe the word in English so I might be able to provide them with new 
vocabulary that is relevant to them. Research done by Jo Anne Kleifgen and Ofelia Garcia (2010) in their book Educating Emergent Bilinguals: Policies, Programs, and Practices for English Language Learners has shown that "Social justice for emergent bilinguals includes providing them with a challenging inclusive and linguistically and culturally relevant curriculum that empowers them..." (p. 127). Due to this research, I attempt to include student interests in my lessons to make them more relevant; for example, when Yvette mentioned that she enjoys crime shows, I used a Crime and Puzzlement activity for the Do Now a few days later.

Assets \& Needs: Funds of Knowledge. Yvette's identity became much clearer to me as soon as I conducted a scheduled home visit. I drove the mile from the school to Yvette's house, arriving early, as I always do. I parked on the street, unsure of where I should be. The house next to Yvette's had a fence blocking off the front yard from the sidewalk. Inside, a German Shepherd Dog prowled back and forth, pausing occasionally to bark at passersby. When the time of our meeting got close enough, I nervously left my car and walked up to Yvette's house. I knocked on the front door, listening to the screeching of birds just inside. A middle-aged woman peered through the screen and asked what I wanted in Spanish. I stumbled through an explanation that I was a teacher, there for Yvette Rivas. The woman grumbled that no one by that name lived at the house, and closed the door.

I walked back out to my car, now twice as nervous. Had I gotten the address wrong? I frantically called Yvette's father, and explained to him in broken Spanish that I was outside what I thought was their house. He told me I was in the correct spot and that he'd call his wife so she could help me find the house, as he was at work. Finally, Yvette came out to the sidewalk and found me. She led me to a house behind the one I had originally believed to be where she lived. I met her mother in the driveway. Mrs. Rosa Rivas is a kind, soft-spoken, Spanish-speaking 
woman with a wicked sense of humor; I immediately knew that this was most likely from where Yvette had gotten her love of pranks. I greeted their small dog, Luna, who had been kenneled for my comfort, in case I was afraid of dogs (I am not, but the gesture was quite thoughtful). At this moment I was still incredibly nervous; all of this was a very new experience for me.

I continued to fret right up until I stepped foot in the house. Then, it was as though I'd been transported to another world. I was instantly at ease in the Rivas house. Gleaming wood floors covered the living room and led forward into the rest of the small house. To my right in the living room, beautiful wooden crosses covered one wall, a table with candles and photographs beneath them. Also in the room were a TV and sofa and chairs, but that far wall of religious artifacts captured my attention. I was led further into the house, which smelled of clean air and contentment. I was reminded powerfully of my grandparents' home in Minnesota; there was a certain similarity in the smell: wood, warmth, and the faint remnants of home-cooked meals and cleaning products lingering in the air. To one side in the narrow hallway, there were two closed doors: bedrooms, I assumed. To the other side was a door partially open, through which I could see the glow of a TV that displayed a game of Fortnite in progress.

Once through the hallway, we entered the kitchen and dining area. In that room, there was a door leading outside to a small backyard. The kitchen was spacious, with cooking utensils displayed carefully and arranged for ease of use. I could tell that the kitchen was well loved and frequently used. On the walls, more sculptures and crosses were hung. The house in general was small, yes, but incredibly beautiful and welcoming. Yvette, Mrs. Rivas and I sat around the table, and were joined shortly by Yvette's brother, Daniel, who would be helping to translate. I first asked Mrs. Rivas what Yvette's special talents or interests were and quickly saw her sense of humor when she responded first with "eating” (R. Rivas, Personal Communication, 2018). She 
then got a bit more serious, and surprised me with the answer of "singing and dancing." Yvette had never mentioned such interests to me, and given her reaction, I believe she is somewhat embarrassed by them, but as I relate to her love for them, I was delighted to have this new insight.

The family speaks Spanish and is clearly quite close. They frequently play soccer together and cook meals in the evenings. Mrs. Rivas stated that if she could teach Yvette anything this year, it would be how to cook. She said that Yvette has always been funny and outgoing with the family, but that sometimes she can be shy with new people and large groups. She went on to say that Yvette is kind and diplomatic, and so "should maybe be a flight attendant" (R. Rivas, Personal Communication, 2018). Yvette countered with "No, president or lawyer," and her mother smiled and nodded indulgently (Y. Rivas, Personal Communication, 2018).

Mrs. Rivas truly values education. She was only able to attend school until $6^{\text {th }}$ grade, and she stated that she wishes she could have had more of an education. That's why she wants Yvette to work as hard as she can and get the most out of school possible. She believes that the role of the school is to act as a conduit of sorts for education to happen; the teachers are responsible for aiding in the student's progress. Teachers are there to support students and guide them.

The Rivas family enjoys going out to eat together for birthdays. The family consists of Yvette, her parents, and her older brother. Both of Yvette's parents are from Mexico, but she and her brother were born in America. The family also makes tamales together and plays soccer. They are a deeply religious family, and also very close. It is clear that they love each other and spend a lot of time with each other. Prior to making this first home visit, I had assumed that I would remain uncomfortable for the entire visit, unable to find much common ground between 
myself and the parent(s) of my students. I was pleasantly surprised that this was not at all the case; in fact, it was quite the opposite. To continue deepening my understanding of Yvette, I next interviewed her alone.

Assets \& Needs: Experiences, Interests \& Developmental Considerations. When welcomed into my classroom for her interview, Yvette immediately crossed to my desk and picked up my pen. I reminded her of how we respect personal belongings in the classroom, and she apologized and placed the pen back where it had been. The exchange has become something of a ritual for us, as it happens almost every time we interact. I first asked Yvette what she enjoys doing in her free time and what she would like to do for a career. She told me that she enjoys singing, dancing, drawing, and sleeping, and that she'd like to be an accountant when she grows up. As math is her most difficult subject, I asked her why she wanted to be an accountant. She replied that it was because it was a stable job with fairly good money. She's extremely practical. She then restated that she also would like to be a lawyer or the president, but that those maybe aren't realistic dreams. Yvette couldn't think of many major events that had influenced her, but she did again reference her family and how close they are. Having their support and input has been a major influence on her life. It is for this reason that her family, especially her father, has been the most influential figure in her life, for very positive reasons.

Yvette largely enjoys school, though she admits to getting bored a lot, particularly in math and history classes. She is most successful in her English and science classes, and least successful in her math and history classes. She finds English and science interesting, so she is more willing to work on the skills necessary, but she feels math is impossible and history is too boring to do any of the work. I believe she benefits from more cultural relevance in her English and science classes, a strategy that, according to Ladson-Billings (1994) can help students be 
more engaged in the lessons. Culturally responsive teaching relates what a student learns to his or her own life, and recognizes the cultures present in the room thus making it more accessible to more students. Due to her EL status, Yvette sometimes struggles with understanding directions and reading for all the subjects, but her mother's dedication to the belief in education has resulted in a fairly hard-working student who believes success is possible.

Yvette is most comfortable in her room at home, but she says that at school, she is most comfortable in my classroom because I "let her be herself" and help her when she needs help without making her feel "stupid" (Y. Rivas, Personal Communication, 2018). She is least comfortable in the math classrooms because she always feels like she doesn't know what she's doing in those rooms and it's a very insecure space for her. Out of school, Yvette has a very involved family to lean on for support. In school, she has her other teachers and me, and the school counselors who are always there to help her if she needs it. Yvette's development has been fairly typical her whole life according to her mother and the teachers at the school who knew her as a $6^{\text {th }}$ grader. She has no IEP and no documented need for an evaluation.

Action Plan. Based on my now-deeper knowledge of Yvette and her academic strengths and needs, I have developed an action plan for her continued educational growth in English class. First, I'd like to be sure that when I ask Yvette to work in a group, there is both individual and group accountability. She excels at working with partners, but I want to diversify her contribution to the group by assigning each student a different role each time group work is done. In Checking for Understanding, Fisher and Frey (2007) quoted Johnson and Johnson's 1998 work as saying, "A common element in the findings about successful cooperative learning groups is that there should be both group and individual accountability" (p. 82). If Yvette simply repeats the same task over and over again without paying attention to how she is contributing to 
the group or how others are contributing, she isn't getting as much out of the activities as she could be. It is necessary for her to evaluate her own performance in order to be accountable for the work her group does.

In order to support Yvette's lexile and vocabulary growth, I am going to start providing more word banks tailored to her individually. In addition, I will begin implementing "Juicy Sentence Protocol" (students examine a mentor sentence from a text they are reading in class, then form their own sentence following the template of the mentor) in the warm up activity for class. In his article, "Making the Most of Mentor Texts," Kelly Gallagher stated: "Before our students can write well in a given discourse, they need to see good writing in that discourse" (Educational Leadership, 2014). Having an example for students to follow will augment their writing. I cannot expect any of my students to be able to write a beautiful sentence without having studied how one is formed, much less my English Learners such as Yvette. I will also continue incorporating more visuals in my lessons to engage Yvette's thinking. I will continue to provide her with sentence frames and starters, and she will be seated with a language buddy who can help her if she encounters difficulty. I will focus on a new grammar concept every couple weeks for the class as a whole, using Do Now time to drill correct spelling and grammar to help push for habitual use of English language conventions. In addition to all of these strategies, I will be in touch with both the English Learner Lead at my school and Yvette's designated EL teacher to focus my lessons with her based on what she needs in that second English class as well as my own.

Socio-emotionally, I will seat Yvette with students she gets along with, and I will continue to remind her each time she takes something that doesn't belong to her without asking that such behavior affects other people negatively. In addition, I will work with the school's 
counselors to ensure Yvette gets any help she might need in the event of emotional need. I will also be in close contact with her family members to alert them that extra support might be necessary should that need arise.

In order to continue to assess progress toward Yvette's academic goals, I will be looking for improvement in summative assessments mainly, and in particular, standardized assessments such as the benchmark test. It is my hope that in the next quarter, at least one of Yvette's areas of struggle will have seen improvement, if not all of them. As for her socio-emotional goals, I would like to see Yvette get through a class period without needing to be reminded to keep her hands off other people's belongings. I will accomplish that goal in small increments, setting small benchmark goals with her. For example, for the first few days the goal will be that I only have to remind her three times or fewer to not touch what doesn't belong to her. Hopefully from there the frequency of needing to remind her will continue to drop. When I discussed this plan with Yvette and her mother, the two did not have many questions at first. Then, Yvette wanted to know if this would make her stand out in class. I told her that I would make sure to not be obvious about giving her other work or help. Mrs. Rivas asked how I could let them know how Yvette was doing in class, and I agreed to call her with an update every two weeks, with more frequency around when the summative assessments and standardized tests are scheduled. Yvette then asked: "Does this make me a V.I.P.?” To which I, entirely truthfully of course, responded “yes” (Y. Rivas, Personal Communication, 2018).

\section{Case Study 2: Daisy Sanchez}

Demographic Information. Daisy Sanchez walked into the classroom on her first day of $7^{\text {th }}$ grade with her lips pursed, her hair tied back in a low ponytail, and her nose in a book. She didn't make eye contact with anyone in the room, including me. She went straight to a desk in 
the back of the room, slid into the chair, smacked the still-open book on the table, and continued to read even through the yelling of students returning to school. After the bell had rung, I went over to her and asked her name. At first, she was completely unresponsive, and it took my squatting down next to her desk for her to notice me and answer. She startled a bit, looking up from her book, and said, without a smile and with an unexpectedly deep voice, "Daisy." I asked her to put her book away for the moment, as class had started, and she apologized, saying she hadn't noticed the bell ringing. As we completed first-day icebreakers, I noticed that Daisy was very reluctant to engage with her classmates or with me.

The trend continued throughout the start of content lessons; Daisy was reluctant to work with anyone else, asking frequently if she could work by herself. In addition to preferring to work alone, Daisy also seemed to be easily distracted: not by other students, but by her own mind. She didn't speak to others frequently, but was often off-task, simply sitting and staring into space or attempting to pull out whatever book she was currently reading. I asked her once what she was doing as she sat there without working or speaking, and she replied that she was thinking about her book. "The book you're reading?" I asked her. "No," she replied, "the one I'm writing" (D. Sanchez, Personal Communication, 2018). I asked her what it was about, and she told me it was about the world in her head.

Daisy's imagination is one of her greatest strengths. She is also a voracious reader, a creative writer, and an incredibly loyal friend to those few people who she allows into her inner circle. She is quiet, but has extremely powerful thoughts that are always carefully formulated before she shares them. A couple of weeks into working with Daisy, I wondered if she was on an IEP that I simply hadn't yet received. Based on her need for quiet, her overwhelming desire to 
work alone, and her distraction, I thought it likely that she would have at least a 504 plan, but she did not.

I believe she would be a good candidate for one, however. The ability to use headphones and take short breaks could aid Daisy's academic work capabilities: it would allow her to focus and participate with others for short periods of time if she weren't constantly bombarded by stimulus from her classmates. In the mornings, for example, when she comes into my classroom and we chat before the day begins, she is at ease and totally focused. She usually has one ear bud in, and has not yet had to cope with the presence of many other students. During these times we are able to discuss at length topics such as baseball, literature, and music. Her attention span and desire to speak in these moments is a somewhat shocking contrast to what I witness during class time. Daisy is an extremely intelligent student with an enormous amount of potential. I am already seeing it, but I think with the aid of some relatively small accommodations, she could be even more of a leader and asset in the classroom.

Assets \& Needs: Academic Standing. Daisy is classified as an RFEP, and her entire family speaks English at home, though I believe not exclusively, as she is verbally fluent in Spanish. I do not know when she reclassified, that data is not listed in her information. Her RI score, tested in August, was proficient at a lexile level of 1104. Her iReady score, also tested in August, is one level below proficiency. When she is able to focus for long enough, Daisy completes formative and summative assessments at a very high level. She makes very few spelling or grammatical errors, and her vocabulary is extensive (see figure $3 \mathrm{~A}$ ). She currently has an $88 \%$ or $\mathrm{B}+$ in my class and grasps most concepts fairly easily. On a recent benchmark test, Daisy earned a 77 percent, significantly higher than many of her peers, even with her difficulty 
focusing (I witnessed her sitting with arms folded staring at the wall a total of six times during the 1.5-hour test, each instance lasted an average of two minutes).

Independently, Daisy is able to complete most work at a very high level of accuracy fairly quickly. She can sometimes succumb to her distractions for too long, resulting in unfinished work, but she is amenable to redirection. Daisy's largest struggle is in group work. As stated previously, Daisy asks to complete all work by herself. She only shares answers or opinions if prompted, and at times will go rogue and work alone even when told to work with her group.

Typically, Daisy will complete assignments as directed no matter the content (aside from group or partner assignments). She is very resistant, however, to annotation, preferring to simply read a text rather than make notes and observations on it in writing. Her annotations are few and far between even when given very specific instructions regarding what to look for, and she instead will just read through the text. While this sometimes works well for her, (usually with literary texts) I believe it to be part of the reason why she struggles with informational text despite her high lexile level (see figure 4A). While she is able to read the individual words, she does not make a connection to the text and from word to word to produce meaning in informational text. With literary text, she is used to the format and is able to connect through the plot and characters, and thus can form the images to make meaning with her vivid and powerful imagination.

Overall, Daisy is a very creative student. She is currently 10 hand-written pages into a novel she is writing, and is constantly creating new chapters and characters in her mind. She has a broad vocabulary and uses it to her advantage when completing assignments. Her critical thinking skills are also quite strong. She is able to solve problems for herself and determine a course of action based on her end goal without much teacher intervention. She does frequently 
struggle to follow through on that course of action if her book or her imagination sidetracks her. Her largest difficulty is in communication. She avoids talking to and working with others and almost never makes eye contact. She is really only comfortable when speaking with someone with whom she has made a connection in a one-on-one setting, and even then, it is difficult for her until she warms up into the conversation.

Daisy struggles most with the informational text standards such as CCSS.ELA.RI.7.1, ELA.RI.7.2, and ELA.RI.7.6. She has difficulty determining the central idea of informational texts, finding evidence within those texts, and analyzing the point of view of the author and the author's purpose. On the recent benchmark test, Daisy answered all five informational text questions incorrectly. I believe this is partially due to her difficulty focusing, but also partially due to the earlier-described inability to connect to these informational texts and make meaning from them. She is able to read each word individually, but making sense of the text as a whole continues to elude her. This is in direct contrast to her phenomenal success in the RL standards. On the benchmark test, she got all but one of the RL standard questions correct, scoring a 7/8. When reading literary texts, Daisy is able to easily connect to the main ideas, plot, and characters. I believe this is in part simply due to the vast amount of practice she has had with literary text. As she reads novels constantly, she is more familiar (subconsciously at least) with their forms and tendencies, and thus has an easier time making meaning from that type of literature. I believe with more practice and more connections made between literary and informational texts, Daisy will be able to perform equally as well with both types.

\section{Assets \& Needs: Socio-Emotional Development \& Social Identity. Most of Daisy’s} needs are not academic in nature, but rather interpersonal. She is very strong in conversation that is one-on-one with a trusted partner, but she becomes resistant to talking again the moment there 
are other people in her surroundings. She struggles to make eye contact and can sometimes come across as painfully blunt and/or rude. She at times will say something to another student that is perhaps not typically thought of as being polite (e.g. "You don't know that word? You're stupid" or shouting, "You sound like a girl!" at another student). Daisy also struggles quite a bit with not rising to engage in verbal sparring matches. There are students in the class who know how to get her to react (usually by insulting her or her family), and they consistently attempt to push her buttons. Daisy will always yell back at them, thus getting into trouble as well and having a harder time focusing on the work at hand.

In class, I lean heavily on discussion of what we are reading, both full-class and also partner or small group. I think these opportunities are crucial for students to begin to learn negotiation tactics when having to work with others. I also teach proper eye contact and vocal projection whenever we have a more speaking-heavy day of assessment. I include reflection questions for students to complete that can help Daisy learn about self-awareness, particularly when it comes to group work. She will be able to think deeply about how she performed as a group member; not just in doing the work, but also in terms of how she was able to navigate the relationships within the group. This goes hand-in-hand with self-management.

Also available to all students, including Daisy, is the ability to have a growth mindset by attending Office Hours and doing extra work or redoing work to achieve a better grade. This type of growth mindset ensures that students are pushing themselves to do better but also still learning all of the concepts necessary. Daisy is in my advisory class as well as my English class, and so I am able to help her with these Socio-Emotional Development needs even more frequently throughout the week. In advisory we have specific SEL (social-emotional learning) lessons that cover topics like self-management, growth mindset, social awareness, and relationship skills. 
From these lessons students will learn strategies and theories behind each of these facets of their socio-emotional development, and I will be able to further reinforce them with Daisy in a more traditional classroom setting. Her relationship skills in particular will continually be tested as she works with others in the room, but I think with practice, specific partnering, gentle guidance, and patience, she is capable of having positive interactions with her peers.

When asked how her best friend would describe her, Daisy had a halting description to give, stammering “...uh, kind of annoying, funny...noisy...a bit of a short temper” complete with a self-deprecating chuckle at the tail end (D. Sanchez, Personal Communication, 2018). This is the Daisy that I have encountered when speaking one-on-one in the more recent weeks of school, but it is rare that she is noisy in large group settings. Her temper definitely makes an appearance in all areas of her life, however. She is competitive (usually quietly so, but not always) and can be very loud when she feels as though she should stand up to someone. At times she has difficulty refocusing on work because she is so engaged in a cross-classroom fight. I have witnessed her passion for sports and literature, and her humor when speaking to her in a small trusted group or alone. I always place Daisy in groups for class work that I know she is comfortable in, to encourage her to share her opinions and thoughts. She wishes to become a leader, and I believe she will meet her goal if I continue finding areas for her to feel safe within the classroom so that she can be her authentic self.

Assets \& Needs: Funds of Knowledge. Daisy’s family was not comfortable with a home visit, the reason for which became slightly clearer in Daisy's personal interview (which I will discuss in the section following this one) and so we met at a McDonald's down the street from the school. I was slightly more comfortable for this second "home visit" both because I knew more about what to expect, and also because we were meeting on neutral territory. I felt less 
awkward, less like an invader into a family's personal space this way. The McDonald's looked and felt the way most McDonald's do in my experience; slightly dim, very loud, with the smell of frying oil wafting throughout the area. I spotted the Sanchez family quite easily, and as I slid into the red faux-leather booth, Ryan Sanchez, Daisy's father, slid a large container of fries to me, apologizing for the lack of ice cream, but the machine was broken. Ryan was entirely decked out in baseball gear in support of the local team, and it became very clear with whom Daisy shares her love of baseball. Also present were Maria Sanchez, Daisy’s mother, and Andrew Sanchez, Daisy's younger brother.

I made small talk with Ryan and Maria, but Andrew received the lion's share of my attention, as he was adorable and clearly very sleepy. Indeed, roughly five minutes into the interview he fell asleep on his father's lap in the middle of the loud and busy restaurant. Daisy's love of reading is apparently due to her Tio's influence from an early age. The rest of the family also enjoys reading, but not the same extent. The first thing Daisy's parents had to say about her was that she really likes hot Cheetos. Quickly following their chuckling over their daughter's eating habits, they added that she has a fantastic imagination and is very good at reading quickly and reading a lot. Before he succumbed to slumber, Andrew stated (A. Sanchez, Personal Communication, 2018) that his sister is "...nice. Sometimes."

The family cares deeply about education. Maria especially was vehement in her statements in support of a quality education for her children. She and Ryan both want a good career for their daughter, something that will allow her to live well. Ryan specifically mentioned (R. Sanchez, Personal Communication, 2018) a desire for Daisy to "be her own boss, so she doesn't have to follow what anyone else wants." Maria expressed a bit of concern over Daisy's performance, worrying that Daisy would get sidetracked, but also worried that she would push 
too hard and Daisy would rebel rather than working harder. Maria and Daisy's uncle both are large influences in Daisy's educational life, consistently pushing her to do better and work harder. Maria mentioned Daisy's tendency to get distracted, and her difficulty with concentration and with group work. Both Maria and Ryan had gone to school nearby and remembered being in middle school and working very hard in school because to them it felt like their free time. At home they would have chores to do, they remember the neighborhoods being worse even than they are currently. Ryan had stories about having to run home from school in an attempt to avoid getting involved accidentally in any gang activity. School was a safe place for both of Daisy's parents where they could be themselves and have what they felt was fairly easy and interesting work to do. They both believe that teachers are there to support students and to push them just as parents do, and the school should be a place of protection for the students who are there to learn. The family enjoys spending time together, could be for scheduled "fun" activities, or it could be something as simple as Target. "The point," as Ryan put it "is to spend time. With the family, all together" (R. Sanchez, Personal Communication, 2018). Frequently they will go out for movies or sushi, and they have begun spending time exercising and going on short hikes nearby. Ryan believes the family should focus on health quite a bit, so they are able to "enjoy every year." As he continued to explain his health philosophy, Maria kept a gentle, accommodating smile on her face, making eye contact with me every so often and giving a slight roll of her eyes seemingly to indicate that while she found her husband's enthusiasm adorable, she did not expect said health craze to last. Indeed, at the end of Ryan's impromptu health lecture, Maria laughed a bit and said, "I give it two months" (M. Sanchez, 2018). The family values their neighborhood but wishes overall that the people living there treated it with more 
respect. There was a general consensus that there was too much trash everywhere, and that sometimes the people in the neighborhood weren't very easy to get along with.

I was surprised by how much the parents had to say about their own educational experiences. They had a lot to say on the matter and were fairly clear as to how their experiences continue to shape their expectations for their children's education today. School is to be treasured, a place to learn and grow without the influence or pressure of outside forces.

\section{Assets \& Needs: Experiences, Interests, \& Developmental Considerations. When I} interviewed Daisy alone, she was visibly nervous. She couldn't make eye contact, she spoke in one-word answers, and she made herself as small as possible in her chair. I reassured her, letting her know that this was essentially just a normal conversation, and not something that would affect her grade at all. She loosened up a bit as we spoke, falling into our normal patterns and beginning to make eye contact with me. She isn't sure what she wants to do for a career yet; she listed veterinarian, archaeologist (though she didn't know the word, saying instead "a person who looks at old human bones" (D. Sanchez, Personal Communication, 2018).), and astronomer as potentials. She was emphatic about not wanting children, and equally emphatic about wanting lots of pets. She wasn't sure about whether she'd want to get married or not, it seemed to be another aspect of her future on which she was not entirely decided.

She likes the neighborhood in which she lives for the most part, but she laments the fact that there is so much trash in the area. She also mentioned that "there are still...you know...bad people" who make their presence known in the neighborhood, but for the most part she says that it's quiet and the neighbors are nice. She is still not comfortable walking without company however, and when asked she stated that she is least comfortable "When I'm out on my own" (D. Sanchez, Personal Communication, 2018). 
One of the most major events that has shaped Daisy's life is her uncle's influence on her reading. He has also most likely been the most influential figure in her life. She reminisced about sitting with him for hours, his handing her the first Harry Potter book and telling her to read as he read alongside her. She and her family both attribute her love of reading to his influence, and she said that he's a major reason for why she likes English class so much.

While English (and reading) is Daisy's favorite school activity, she is least successful in math, and she dreads going to her math classes each day. She enjoys school, but wishes it were a bit calmer. She liked having every period every day last year, when the school wasn't on block schedule, and she thinks the new schedule is confusing and stressful. She said she "gets stressed" when everything is loud, and students are running everywhere in the hallways. She also doesn't like working with other people, saying that she wishes she could work by herself all the time.

Daisy values school and the work she is asked to do there, and this is largely due to the attitude her parents have toward education. Her mother is constantly pushing her to do more and do better, and her father is a slightly less strict but equally persistent pressure. Her parents keep track of how she is doing; they value communication from Daisy's teachers and like to know what she is learning. Daisy as a result is held very accountable at home in addition to in school. Other family members of hers have at least some college education and as mentioned before, her uncle believes quite strongly in reading. Daisy finds the work interesting for the most part, particularly when doing reading or writing assignments for English classes, and so she always has a good attitude toward that work. She is most comfortable in the classes she excels in, working by herself and holding herself accountable. She is least comfortable in her math classes where she feels as though she can't complete the work quickly or accurately. She is also very uncomfortable working with other students or in situations that are loud. 
Daisy is fortunate in that she has a very large support network both in and outside of school. Her parents are there to help her and push her, and she said that she feels most comfortable "around my dad because he comforts me, I know nothing's gonna happen to me" (D. Sanchez, Personal Communication, 2018). That kind of support is crucial for any student, in particular one who has some of the same social challenges that Daisy has. In the school, Daisy's teachers are all there to support her, and she also has the support of two school counselors if she needs it. She makes use of these services at times when she is feeling particularly overwhelmed or distracted by the social interactions each day demands.

Daisy's development is fairly typical. No teacher or counselor has made any mention of any developmental concerns, and indeed, the only concern I have is her discomfort and at times true inability in interacting with others. She struggles to focus and work with other students, but I do not believe it is due to a developmental problem.

Action Plan. In order to aid in her growth both socio-emotionally and academically, I have created an action plan for Daisy that will develop her skills in both areas. In her article "Preservice Teacher Application of Differentiated Instruction," (2011) Amy Lynn Dee states, "Using the IEP (Individualized Education Program) as a guide, teachers must plan for incremental objectives for identified students rather than focusing on the state curricular goals for the grade level" (p. 54-55). In working with students who have different needs, it is important to set goals that begin at the level of the student and work from there, rather than automatically expecting those students to leap to the grade level curricular goals. Because Margaret E. KingSears' (2008) research shows that an increase in teacher preparedness and differentiation for teaching those identified students results in greater achievement, I have crafted a series of goals for Daisy (p. 59). 
First, for her work on social skills, I will continue to ask Daisy to share more and more in class. I will begin by continuing to pair her with her peers and at times allow her to work independently if she is struggling with being overwhelmed, but more and more I will wean her off of such strategies. The ultimate goal is to keep Daisy accomplishing all of the general education work that her peers are doing, since, as Margaret E. King-Sears wrote in her 2008 article "Facts and Fallacies about Differentiation," "Students with Disabilities CAN Learn the General Education Curriculum. Focus on the "How"' (p. 57). While I cannot say that Daisy certainly has a "disability," she does certainly struggle with accessing parts of the curriculum due to her difficulty focusing, her feeling overwhelmed when noise and activity in the room becomes too loud, and her avoidance of working with others. Rather than write those partner activities off for her, believing that she cannot complete them, I will differentiate for her and work with her to allow her to access the same curriculum that other students receive.

For example, instead of just letting her work alone, I will begin to act as her partner if she cannot handle working with a peer. Then, she will be expected to always work with peers, sometimes with classmates she is not as comfortable with. Before asking that of her, I would allow her to get to know those new people, utilizing whole-class check-ins and small community builders and ice breakers to help her gain greater comfort with more of her peers. Gradually I will have her mostly working with new classmates each day and only occasionally working with her close friends. She is fully capable of completing the work the general education curriculum entails, and I will make sure to treat her as such. In addition, I will monitor her progress in speaking and listening standards that relate to formal discussion; in particular I will be paying attention to her use of eye contact and proper volume. I will also continually remind her of the expected way of engaging in academic discussions. I will coordinate with the school counselors 
to make sure Daisy is supported throughout this process as it might at times become stressful for her. I will also be attempting to get certain accommodations for Daisy such as the use of one earbud to limit her being overwhelmed by noises, and the ability for her to take short breaks in the hallway where it is quieter during class. My hope is that with the proper support and gradual progress, Daisy will be able to dramatically improve her ability to interact with peers without it being too overwhelming.

Academically, my goal with Daisy is to improve her ability to make meaning of informational texts. She is more than proficient in her analysis of literary text, but informational text seems to be nearly impossible for her to understand, at least based on the benchmark test scores. I am going to make more of an effort in my lessons to always tie informational text closely and explicitly to the literary texts we read in order to hopefully translate her understanding across the forms. I am also going to begin using a reverse multi-flow thinking map (also known as a "wolf map") in order to give her and other students a strategy for determining the central ideas of a text. In such a thinking map, students are first asked to list details they remember or notice in a text, then identify common themes or topics between each of these details. From these themes, they will be able to determine and construct the central idea. I would also like to encourage Daisy to engage in the informational texts we read in a more creative manner, since she has such a vivid imagination. For example, I will give her opportunities to craft her own art or literary stories based on informational texts read in class. It is my hope that putting informational text in a more literary context will enable her to grapple more productively with the meaning of those texts. I have communicated with Daisy's other English teacher and she will be using similar strategies to augment Daisy's interaction with informational texts. 
In order to assess Daisy's progress, I will a few different strategies. For her social development in an academic setting, I will mainly utilize close observation. I will be able to monitor her comfort level when communicating with various different partners in the classroom, and I will make notes each class with regard to her ability to maintain eye contact and work with others for extended periods of time. Academically, I will be relying on formative and summative assessments in my class, and ultimately will hopefully see improvement in her next benchmark test scores. I will continually test the students using text-dependent questions for informational texts and I will ask them more generally to complete "wolf" maps to construct paragraphs detailing the central ideas of various informational texts.

I told Daisy's parents about this action plan and they were very receptive to it. Her father gave it a nod and a "thumbs up," and her mother told me to let them know if there is anything they can do to help. I responded that they should continue being supportive, particularly if Daisy encounters some difficult days especially when we work on her social development in academic discourse. The only question either of them had was about if/how I would be able to keep in contact with them to update them on Daisy's progress. I responded that I could have as much or as little contact with them as they liked, in whatever medium was most convenient to them. Daisy of course will be receiving grades and have small check-ins with me so she will know how she is progressing. Her parents decided they would like me to email them once every other week to notify them of progress and any difficulties encountered.

Daisy's support system is dedicated and enthusiastic, and I am confident that with their assistance, and mine, she will be able to make huge strides both academically and socially in a very short time. Above all, what I would like to keep in mind as I help guide her on her path to greater comfort in the learning environment is the idea of culturally relevant critical teacher care 
as named by Mari Ann Roberts (2010). Elizabeth Bondy and Elyse Hembacher (2016) describe this phenomenon in "Let Care Shine Through" as "... a way of thinking about caring for students as a moral imperative, a way to not only offer warm support, but also take steps toward justice for historically underserved children" (p. 50). As a student who has more difficulty than is typical in accessing the curriculum, Daisy is one of those "underserved children." My job, my "moral imperative" is to act as a support system for her and enable her to grow and change and adapt through the goals I set for her. It is my hope that by the end of this year, more of her classmates will be aware of her love for baseball, more will have read her scribbled stories, and more will have learned how kind and generous and funny she can truly be.

\section{Case Study Three: Jonathan Cruz}

Demographic Information. Jonathan Cruz sat at the back of the classroom on the first day of $7^{\text {th }}$ grade and glared at each student who walked in. To some, he gave a short upward nod. To others, he gave no acknowledgment at all. I received a quick glance, a small tilt of the head, and raised eyebrows, but no real greeting of any kind. A student named Brandon sat next to him on that first day, and it appeared that they were the best of friends; they whispered to each other throughout the class, had a special handshake, and walked out together when the bell rang. After that first day, however, I have never witnessed the two students interact in a non-negative way. This seems to be the case for many friendships Jonathan forms: they last for a short time and then explode into negativity and animosity.

My experience as this student's teacher has been equally a roller coaster. There are days when Jonathan and I have a fantastic relationship and he is kind and polite and funny and I feel as though we have made real academic progress — and then there are days where he either refuses to speak to me or he curses profusely about everything he is asked to do, no matter how small a 
task (e.g. writing his name at the top of his paper). When he is having a good day, Jonathan is the type of student I love to have in my classroom: he is engaged, curious, and respectful. After reading the book Scorpions by Walter Dean Myers in class, he asked if there was a second book. When I told him there wasn't, he said someone should write it. I suggested that he might do that, and he was enthusiastic about the idea. This is the type of care and interest Jonathan is capable of putting into his work. The problem that arises, however, is that he is also capable of the exact opposite if not having a good day. On his bad days, he refuses to do any work, curses at other students, shouts, and frequently rips up any handouts given to him.

Jonathan used to attend office hours with me every Tuesday afternoon, spending an hour each week learning more, working harder, and redoing assignments that he struggled with during the previous week. In working one-on-one with him, I saw how determined he was to "get it right," to learn what he needed to know in order to succeed in class. As he completed his work, we discussed video games and how he liked what we were reading. He related heavily to Scorpions because "My brother, um, he's in jail. Like the one of Jamal” (J. Cruz, Personal Communication, 2018). Jamal is the main character of the book, and I think it was comforting for Jonathan to read about someone like him.

Jonathan is high energy, and when he's willing, throws himself into the work we do in class. He enjoys discussion, thrives on debate, and is always trying to predict what will happen next in the literature he encounters. His volatile nature, however, results in his intelligence and creativity not always being evident. He argues with students about outside matters, and thus is not focused on the literature that he sometimes loves so much. He also struggles academically. Jonathan completes work roughly $60 \%$ of the time, and while he loves English, it is a subject with which he struggles. 
Assets \& Needs: Academic Standing. Jonathan is an English Learner, with no more specification given in his official records. His home language is Spanish, and he almost exclusively speaks English only at school. Jonathan performs fairly well on formative assessments, though usually requires extra assistance in completing them. He makes use of intentional scaffolds such as sentence frames and word banks in order to complete them. On summative assessments, Jonathan does not perform nearly as well. It is a struggle to get him to complete them as he feels they are too hard and gives up nearly immediately when faced with the challenge (see Figures 5A and 6A). With additional coaching (e.g. telling him he can do it, to take it one step at a time) he is sometimes able to work through his negativity and complete the assessment at an average of a 70\% accuracy rate, but frequently he refuses to do any work for the rest of the class period once he has encountered adversity. On standardized tests, Jonathan performs the worst, as he is unable to get additional support from his teachers. His latest RI lexile score from October is 313 , well below the grade level standard. His iReady score, tested in August, is listed as " 2 or More Levels Below" the grade level standard. He failed the recent grade-wide benchmark test with a curved score of just $58 \%$. Jonathan answered almost every question incorrectly, which I feel is at least partially due to his giving up on the test and choosing answers at random. As I watched him take the test, I saw him click answers quickly on the computer, not pausing to read the sections of text associated with the multiple-choice questions. He still has a B- (81\%) in my English class as of November of 2018, but his recent increased negativity and reluctance to complete work has resulted in his grade slowly declining.

Jonathan works best independently with significant teacher intervention. Other students distract him, or he relies on them to do all of the work for him when completing group projects. Independently and without any teacher interference, Jonathan struggles to move from one step in 
the assignment to the next and also frequently declares it is "too hard" and stops working. If the work is within his reach academically, Jonathan completes it with little to no issues. If it is outside his reach and he has fairly significant support from me, he is able to complete his work accurately as well. If the work is challenging, however, and he is left to complete it truly by himself, Jonathan will quickly give up and begin distracting other students or yelling about how difficult it is. Jonathan is able to complete tasks as directed if he feels capable and/or motivated, but as soon as he feels slightly discouraged, he will no longer complete the tasks given to him.

Overall, Jonathan is a very creative student with good critical thinking skills and at times excellent communication skills. He enjoys creating new possibilities for the literature we read in class and easily connects one work to the next. For example, on a recent quiz about $A$ Long Walk to Water by Linda Sue Park, in discussing the main character's experience after having lived through war, Jonathan was able to connect that character (Salva) to the main character of Monster by Walter Dean Myers. Making a connection across novels months after we stopped discussing Monster without being prompted shows a tremendous amount of creativity and critical thinking. When he is calm, Jonathan is able to share his thoughts with his fellow students and me, making interesting points and succeeding in communicating them effectively to his peers. Where he struggles in all three of these areas is when his ability is overshadowed by his attitude. Jonathan struggles to remain calm when others disagree with him and allows a small amount of difficulty in activity to affect his work beyond just that area of difficulty.

Jonathan struggles with most of the content standards. His command of English is only in basic communication, and so without assistance, much of the work done in the classroom is beyond his language skills. He struggles with reading comprehension for both literary and informational texts and stumbles over grammatical conventions (CCSS.ELA.RL.7.2, 
ELA.RI.7.2, ELA.L.7.1). I believe this to be due almost entirely to his English learner status. Once again, on his benchmark test where he was given no additional assistance, he answered nearly every question incorrectly, only receiving points for the written portion of the test. When he is given extra support in reading comprehension with the aid of visuals or extra explanation from the teacher, he is able to accurately convey knowledge of all types of texts. He is strongest in ELA.RL.7.3, analyzing how elements of a story or drama interact, and ELA.RL.7.6, analyzing how an author develops and contrasts points of view. Jonathan is quite good at understanding characters and how their environment is affecting them. He is also good at gathering information about these characters and what the plot has been so far in order to predict what might happen next or what the characters might do. As mentioned before, he is also good at synthesizing information and drawing connections, not just within a text, but also between texts and between the texts and his own life.

\section{Assets \& Needs: Socio-Emotional Development \& Social Identity. Jonathan struggles} most with his interactions with other students. One-on-one with me, he can be very kind and funny, always asking how my day has been, but once he is confronted with his peers, he becomes argumentative and hurtful. He is prone to bullying others, saying they're "stupid" or "gay," which he has been told many times is unacceptable. He also has the tendency to shout swear words when he doesn't get his way with things, or when he encounters difficulty in a task. He has also recently gotten into three fistfights with other students during lunch and after school. Other students do not like interacting with him because of his behavior, and unfortunately, it only seems to be getting worse. I feel his attitude and social behavior are due in large part to some of the adversity he has faced outside of the classroom, which I will go into greater detail about later. Jonathan needs to be taught and to utilize ways of calming himself down, ways of dealing with 
conflict, and ways of accepting challenge and persevering rather than giving up and becoming angry about it.

I am able to help Jonathan with some of these areas in one-on-one conversations and by placing him in groups with students with whom he does not have conflict. He also receives lessons in his advisory around these SEL (social and emotional learning) topics, though I do not personally teach him, as he is not in my advisory. I am working with Jonathan to recognize when he is getting angry and then deal with that anger in a healthy way, rather than lashing out. I will pull him out of the classroom for short conversations or allow him to take small breaks in a quieter space in the room so he can calm down. I am careful with whom I place him for partner or group work and attempt to visit his partnerships frequently to ensure conflict isn't beginning. As facilitator of his group work, I coach him through his interactions with others, providing him with academic sentence frames to help him interact with others in a more measured and calm way.

Jonathan speaks Spanish often and feels a deep connection to others who speak the same language. He recognizes that his neighborhood isn't very safe, but he feels part of it still, telling me stories of when his neighbors helped his family wash their car, or when the children in the neighborhood would find time to "hang out" together. He speaks frequently of wanting to be a man, and that he should be strong and able to take care of everyone else in his life (J. Cruz, Personal Communication, 2018). He has somewhat traditional values, wanting to get a good job to take care of his future wife and children.

In my classroom, I provide students with many opportunities to connect to the literature we are reading. This has been especially powerful for Jonathan. He has been able to express his worldview and see it reflected back at him in the form of a character from a book, and so he feels 
as though he isn't alone in having these life goals. Jonathan feels comfortable talking to me about what he wants from life and how he's feeling on any given day, often stopping by my room when we don't have class in order to talk with me briefly. I listen to him without judgment, offering advice when he asks for it, and asking him further questions to make sure that he knows I'm interested in his thoughts and paying attention to what he has to say.

Assets \& Needs: Funds of Knowledge. In order to better support Jonathan in his academic and social-emotional journey, I scheduled a home visit with his family to learn more about him and his background. The family was not comfortable with my going to their house, as “it's too dangerous" for people who do not live there according to Jonathan's mother, Elvia Cruz (E. Cruz, Personal Communication, 2018). I agreed to meet them instead at a local independent burger restaurant. I arrived early and waited in my car for a few minutes before walking in. Seated at two adjacent tables were Jonathan and two people I hadn't met: a woman of about 20, and an older man, probably in his 40s. They waved me over to their area, and Jonathan stood to give me our customary high five. The young woman, Angelica, introduced herself as Jonathan's older sister, and the man, Alan, who told me he is Jonathan's mother's boyfriend. I learned more about the family dynamic in my interview with Jonathan, which I will go into later.

Alan and I had a small conversation about teaching and our lives, and he shared that he does construction with a company in his hometown, Morriston. He was very proud of where he was born, mentioning it multiple times. Elvia arrived shortly after I did, coming straight from her work at a daycare center. After the whole family was present, Alan asked what I wanted to eat. I protested, saying that I was paying and thus would take all of their orders instead. He said, “absolutely not," pulling a wad of cash from his pocket, handing a \$100 bill to Jonathan, and telling him to "go get food for everyone" (A. Ramirez, Personal Communication, 2018). 
Shockingly, without asking what I wanted, Jonathan managed to get the perfect food for me-a cheeseburger with fries and a Coke. The food was quite delicious and there were a few minutes that I simply sat with the family and ate in silence. After those few minutes, I asked Angelica what she does, and she told me that she is working on her nursing degree. She would be translating for me as I spoke with Elvia.

I began the interview by asking the three adults what Jonathan's strengths are. They responded unanimously at first with uproarious laughter. Jonathan turned red, but chuckled along with them. The family eventually calmed down enough, and Elvia gave me a serious answer with the assistance of Angelica. Jonathan, they agreed, was very good at video games, but also very good at drawing and coming up with new "inventions" as they called them. Machines, buildings, it seemed that Jonathan was a master of creating them all. This surprised me, as I'd never seen Jonathan draw in class, and I have since made a point to try and encourage that inventive side of him by allowing him to doodle as he listens to the lesson. Alan sometimes helps him with his drawings when they enjoy time together as a family, as he has some knowledge of actual handson construction.

Jonathan's mother grew up in Mexico, and his father was not mentioned in the interview, though he told me that his dad still lives with them at home. It could be that the father was not part of the conversation because Alan was present. Jonathan's mother works for a daycare organization and is gone most of the day that he's at school, and even afterward. His sister, Angelica, is often the one caring for him. The family speaks nearly exclusively Spanish at home, and they always enjoy going to the pool or playing soccer together in the nearby park. The family in general is very team-oriented; the whole family helps with cleaning and cooking. 
The adults described Jonathan as being kind and helpful, but that sometimes he has a very short temper and is quick to react with violence. They believe he enjoys English sometimes, but struggles with it, and that when he takes his time, he excels in science. His sister expressed a desire for him to help her clean more, and his "step dad" wants him to be clean, educated, and have good manners. His mother, through Angelica, told me that she wanted Jonathan to grow to "be more noble" (E. Cruz, Personal Communication, 2018). Overall in life, they all want him to get a career and to "be something in life" (Cruz Family, Personal Communication, 2018). They don't want him to have any particular job, but they want him to be happy and be able to support his future family.

The family in general believes that education is extremely important. Alan believes a good education is crucial no matter what field Jonathan chooses, Angelica is currently in college studying nursing, and Jonathan's mother is glad her son is in America instead of Mexico, where she grew up, because "it is better, there's more opportunity here, more books, more help" (E. Cruz, Personal Communication, 2018). They also think the role of the school is to bring families together in an environment of safety and learning. They wish that there were more meetings at the school in fact, and more festivals for all the students and families to enjoy. Jonathan's mother chimed in with her belief that teachers are there to educate students, yes, but they are also there for "encouragement, to make them eager to learn" (E. Cruz, Personal Communication, 2018).

The family (which for this conversation included Alan rather than Jonathan's biological father) enjoys doing things together, such as going to movies, playing sports, and going out to eat. Jonathan and his 5-year-old nephew watch comedies together frequently, and the family will sometimes all take the day off to go get IHOP pancakes. "Family," Alan explained, "is more important than any amount of work you might get done that day. As good as school is for 
Jonathan, being with his family is also important" (A. Ramirez, Personal Communication, 2018). I agreed with the sentiment. We finished our food, and Jonathan and Angelica took all of the trash and disposed of it for us all. We walked back out into the noise and heat of the city and Alan insisted on showing me his motorcycle he had built himself before we all exchanged "thank you" and "have a nice evening."

In the car on the way home, I thought about what I had learned about Jonathan and how I might incorporate it into my lessons: that he enjoys drawing and inventing things, that he is creative and requires encouragement. I also reflected on the interview I had already done with him and how he had given me another layer of insight into his family and life that I would not have gotten just by speaking with the adults in his family.

Assets \& Needs: Experiences, Interests \& Developmental Considerations. When I asked to interview Jonathan, he took his customary pause before smiling slightly, his dimples appearing on his cheeks, and responding, "Why you wanna interview me?" (J. Cruz, Personal Communication, 2018). I told him truthfully that I thought he probably had a lot to say about things, and that I was interested in his life. He had previously related to the book Scorpions by Walter Dean Myers because like the main character, Jamal, Jonathan has a brother in jail. I found his courage in discussing the matter in front of others, with little negative emotion showing, both admirable and also slightly distressing. How could a student be so apparently blasé about his sibling going to jail? He had told me that his brother had not done anything wrong, but had been hanging out with friends who had had drugs on them. The police caught the group and his brother somehow wound up bearing the brunt of the charges. Again, Jonathan was casual about the discussion. His true feelings, I believe, are expressed through his occasional emotional 
outbursts. Over the course of the interview I discovered that Jonathan had endured much more violent experiences than his brother's going to jail.

I began the interview by asking what I thought were fairly simple questions. First, with whom Jonathan lives. He responded that he lives with his mom and dad, but that his mom has a boyfriend who had just asked to marry her, to whom she has not as yet given a response. Two of his siblings have moved out (one of whom is in jail) and three siblings still live in the house with him. I then asked what his family enjoys doing together, and he responded, "Going to the park, playing soccer for fun, cascaritas" (J. Cruz, Personal Communication, 2018). I asked him what "cascaritas" meant, having not heard the term before, and he told me it was "like a quick match. I think” (J. Cruz, Personal Communication, 2018).

I then asked him what he likes about his neighborhood. He was silent for about 30 seconds, and then he shifted in his chair, cleared his throat, and said "not much" (J. Cruz, Personal Communication, 2018). He elaborated on his response, telling stories of the local gang. They crashed into his brother's car drag racing once, another of his brothers had to duck down behind a car because they were shooting in the streets, and once when Jonathan was in $3^{\text {rd }}$ grade he and the other children at recess had to drop to the ground because gunshots were flying nearby, and "a gunshot landed 10 feet away" (J. Cruz, Personal Communication, 2018). Throughout all of these stories and descriptions, Jonathan had a bit of a gleam in his eye. It wasn't from the content of the story, but from the telling of a story in general. I had seen this gleam before; Jonathan enjoys telling stories, he likes to get reactions from his audience, he loves to hold people in suspense and then shock them with what happens next. He is a creator of stories at heart, and that is why he wanted to write "Scorpions Two" as he called it (J. Cruz, Personal Communication, 2018). 
As a sort of focus to this section of the interview, I next formally asked Jonathan what he would change about his neighborhood. He said he would like there to be no gunshots or gangs. He told me another story of a gang member being shot dead a block away, hearing the shots, screaming, and the sirens. I feel it is little wonder then that while Jonathan sometimes feels school is boring or annoying, it is also where he feels the safest. He feels least safe "outside next to where the gang [sic] are" (J. Cruz, Personal Communication, 2018). While school can be difficult for him both academically and socially, at least he is free from the sound of gunfire or the concern that he will have to avoid being shot.

He enjoys and feels most comfortable in English class because he likes describing people, and he has a good memory. He likes to draw, and likes science, but he says he's bad at it and doesn't feel comfortable in that class “because, um, like, I wasn't paying attention in $6^{\text {th }}$ grade" (J. Cruz, Personal Communication, 2018). His mother, he told me, used to tell him and his siblings stories before bedtime at night when they were all younger. This is perhaps why he has such a close connection to storytelling himself. He likes a lot of the books read at the school like Lupita Manana, Scorpions and Esperanza Rising because he sees himself in them. He sees similarities to his own life, and even sees some of his aspirations reflected in the characters'. Throughout all of these stories, there is the desire to earn more, to not just survive, but also thrive, and to do what is necessary to achieve that goal.

When he is older, he wants to "be a police" (J. Cruz, Personal Communication, 2018). He wants to have two children, one boy and one girl, he wants to have a wife (who he will "date for ten years - NO one year" and then propose to) and he wants to have a Siberian Husky (J. Cruz, Personal Communication, 2018). Jonathan has a very detailed life plan figured out, and he 
becomes visibly excited discussing it. It's as though he's getting to tell the story of his own life before he's lived it, and this brings him joy.

In school, Jonathan really only has one friend, Andres. When asked to describe his friend, Jonathan said, "He's weak, and kind to everybody. He was the first kid I met here" (J. Cruz, Personal Communication, 2018). I found it interesting that the first personality trait Jonathan assessed in his friend was his strength. I was reminded again of the area in which Jonathan has grown up, and how that might have changed his perception of people. "Kind to everybody" and "weak" were linked together in his description, as though being universally kind was in fact Andres' weakness. For the rest of his support system at school, I am the only teacher with whom Jonathan interacts beyond the official class time. He has access to the counselors, but when I asked before, he is resistant to talking to them, and has only visited them when he was required to after getting into a fight on campus. At home, Jonathan's sister Angelica supports him the most. Again, his biological father was barely mentioned in this interview, and his mother works long hours. Alan visits the family frequently, but isn't able to be there at all times for Jonathan. His sister is there to make sure he cleans, gets food, and does his work. He said, however, that he doesn't really discuss problems with her. At the end of the interview, I thanked Jonathan, and he smiled slightly, nodded, and shouted "peace" while making a sideways peace sign with his hotCheetos-dust-covered fingers (J. Cruz, Personal Communication, 2018).

Jonathan's development is medically typical in all ways to the best of my knowledge. I have spoken with the counselors and observed him over the course of many days and have seen no sign of any physical developmental concerns. Where his development is far from typical, however, is in what he has experienced in his very young life. It is not and should not be typical for a 12-year-old child to have already become accustomed to dropping to the ground when he 
hears gunshots. I am certain that these experiences have impacted his emotional development and continue to influence his actions and reactions. His development of a command of academic English is weak, but it is improving steadily I feel based on the work I have seen him produce in class.

Action Plan. With the information that I've gained from speaking to Jonathan and his family, and examining his work and past records, I have developed an action plan to support Jonathan's educational growth. I discussed this plan with Jonathan and his mother and sister, and the adults seemed very excited, while Jonathan didn't seem to care at all. His sister wanted to know if this would mean he would have extra work, and I clarified that he wouldn't do anything extra in terms of class work, but that the main difference would be in the support I offer and the structure of his participation in class. They asked that I call them with updates on his progress, and if he was struggling with behaving well in class so that they could support the plan at home as well. This is very good to hear, as His family is clearly dedicated to giving him the best educational experience possible, but Jonathan seems a bit more reserved in his enthusiasm. It is possible that he has difficulty finding a connection between his academic success and future success in the rest of his life, and so I will also attempt to draw a more direct line between what he accomplishes in class and what he might one day accomplish in a career.

For Jonathan, I believe some of his academic struggles and his social-emotional difficulties are very closely tied together and rooted in his traumatic experiences (his brother being imprisoned, and the violence he continually experiences in his neighborhood). Simmons and Brackett (2018) make clear that "The effects of trauma are immediate and long-term" and include "behavior problems," "deficits in attention and abstract reasoning," and "a vulnerability to engage in violent behavior" (p. 5). While trauma is not the only factor influencing Jonathan's 
difficulties in school, it is certainly an aspect of his life that must be taken into consideration as it has been proven to affect children academically and socially.

Academically, Jonathan requires additional scaffolding because he is an English Learner. His academics are also affected by the trauma he has experienced, but it is mostly tied to his behavior in class and so I will address my plan for that aspect in the social-emotional development section. For Jonathan's academic success as an EL, I will use multiple visuals throughout my lessons to try and keep him engaged and also to help him determine the meaning of texts and directions. He will be seated with students who speak Spanish but do not struggle as much with academic English so they can act as his language buddies. I will also use many "turnand-talk" opportunities during my lessons so that students can practice with their peers, a method made better for English Learners when, as described by Jo Anne Kleifgen and Ofelia Garcia (2010), “...using all the linguistic and other semiotic resources at their disposal—Spanish, English, language prompts, drawings, gestures" (p. 78). Instead of requiring all students to adhere to English-only in talking to one another, it is more helpful to allow them the use of all languages available to them. Jonathan does not require translation usually, but will receive slightly simplified directions, with specific academic vocabulary defined for him until he is familiar with the concepts (e.g.: infer, cite, predict, etc.). He will continue to receive sentence frames and starters for writing and speaking assignments, and small grammar assignments will be incorporated into the lesson for the benefit of all my students. Jonathan will also require and be given a lot of extra encouragement throughout each lesson, which will have an impact on him academically, but also behaviorally.

For his social-emotional development and to aid in improving his behavior in class, I have decided on a few different strategies. First, as stated earlier, Jonathan will be given extra 
personal encouragement when faced with individual assignments. This is because when he gets frustrated or feels as though he cannot do something correctly, he refuses to do it at all, choosing instead to disrupt the class with yelling and profanity. Encouragement seems to help refocus and redirect him away from negative behavior. Second, when completing group work, I will keep a close watch on Jonathan's mental and emotional state. If he comes to class and seems fairly levelheaded, I will request that he join the group or partner of his choosing to complete the work. However, if he comes to class already agitated, I will employ a few different strategies as the other students complete their work.

During group work, if Jonathan cannot participate, I will first attempt to get him to work with me as his partner. He will still do most of the work, but I will be there as a calm and guiding influence where his peers may have made him angrier. If that does not work and he is too agitated for even that, I will take him to a quieter corner of the room and have him journal instead about his life, how he is feeling, what he's enjoyed or not enjoyed recently, anything he wants. I will also encourage him to draw about his life if he doesn't want to write. If he is unable to complete the journaling, I will send him on a "special mission" out of the room. For example, I will write a note on a post-it, give him the pass to leave the room, and tell him that I need him to carry the note to the designated teacher and come back with his/her response. Mary Ellen Flannery”s “This is Your Student's Brain on Trauma” (2017) states that “...a brief break for a student on the verge of losing control, and needing to refocus, can be helpful...” (p. 44). This "special mission" is designed to be exactly that; a brief break. It will give Jonathan time out of the stressful classroom environment, it will make him feel important and like he is helping me, and it will allow him to stretch his legs and expend a bit of his energy. When he returns from his mission, he will hopefully be in a place mentally where he can at least journal by himself, if not 
work in a group. It is my hope that continued use of these breaks and calming strategies will eventually decrease the frequency with which they are needed, but as long as the traumatic events continue in Jonathan's life, I feel as though I will be "treating his symptoms" rather than “curing" him. I will, however, continue to encourage him to go to the counselor's office in the hope that he will make use of the services they provide for his mental health. He also will be participating in the same social-emotional development lessons all students take during advisory at the school.

In order to assess Jonathan's progress on all of these fronts, I will use a variety of data sources. First, academically, I will use future benchmark scores and his performance on assessments, both formative and summative to track whether or not Jonathan is making progress in his reading comprehension and writing. Second, for his social-emotional development, I will utilize mainly observation to assess progress. I will be encouraged, for example, if I see Jonathan interacting with more students in a kind and calm way, as opposed to the standoffish and sometimes violent way he interacts with his peers now. I will also measure progress based on how frequently Jonathan needs to not participate in group work.

Overall, Jonathan is an extremely intelligent and creative student, with the potential to be helpful to his peers and other members of his community. His trauma, however, has made his path difficult. It is my hope that by following the action plan I have formed, Jonathan will be able to more consistently show the world his creative, inventive, storytelling side, as opposed to the one he currently displays, which is negative, violent, and pushes people away rather than drawing them in. I am confident he has a bright future and the ability to live the story he has written for himself, but it will undoubtedly take work to achieve those goals. 


\section{Concluding Thoughts on Case Studies}

Conducting research on all three of my focus students was a profound and invaluable experience. I wish it were possible to do such deep information-gathering for all of my students, but I feel as though simply learning about these three students of diverse educational assets and needs has dramatically expanded my ability to create lessons that support my entire class. As a teacher, it is imperative that one knows about oneself and the potential biases one carries. Beyond that self-knowledge, taking the time to learn about one's students allows for the creation of lessons that are culturally relevant and utilize student assets, and also challenging yet scaffolded according to student needs. Knowing your students is the first step in creating lessons and plans to support those students, and that is what this second part of my research has accomplished. Knowledge of the students in my classroom allows me to create an environment that is safe and positive, to support students in their social and emotional growth, and to make use of the correct resources. These are important aspects of teaching that allow all students to successfully learn. From this point in my research and development as an educator, I am confident that I will be able to create lessons that address the needs of all of my students while simultaneously making the best use possible of the assets they possess.

\section{Community, School, and Classroom}

After examining my own life and experience with education, and then diving deeply into my students' lives and experiences, I next turned my investigative eye on the community in which I work. Knowing myself and my students has been crucial to my ability to provide them with the best education possible and knowing more about their neighborhood will only increase my ability to understand them and their background. 


\section{Miro-Community Research}

As I make my way to school in the morning, driving more carefully than usual because of the rain, I exit the freeway and immediately at the base of the ramp come to a massive puddle of water. I drive slowly through, hoping my car is able to continue touching the road all the way across the "lake," and breathe a sigh of relief when I've once again survived the crossing.

As I wait at the stoplight just ahead of the puddle, I take time to examine the surrounding area. To my left is a freeway overpass, under which I can dimly see (as it is dark still at 6AM) large transport trucks parked with boxes sitting nearby, covered by dusty blue tarps. On my right, there is a side street on which I have never seen cars driving. There are empty boxes, clothes covered in dirt and mud, and other miscellaneous items scattered on the side of that road. The grey side of the building adjacent to the side street is covered in red and black swirling lines, the same graffiti that has been there since the summer. Most of the surrounding area is also grey, the only exceptions being the bright green sign for the local Starbucks, and the red sign of the Jack in the Box.

The light turns green, and I slowly drive forward, following a semi-truck making a left turn. I dodge around potholes in my car and decide to get coffee before going to work. Outside of the Starbucks I walk past two women wearing revealing clothing and high heels. One of the women smokes, while the other simply looks out at the street. Inside, the shop is full as it usually is at this time, mostly men and women in bright orange construction vests getting their coffee in line ahead of me. The employees greet me as I walk in; I quickly became a "regular" despite my going there only occasionally, as my drink order is always the same. They are extremely friendly, smiling and wishing me a good day as I do the same with them. The other customers have never attempted conversation with me, but I have multiple times had the door held for me or held the 
door for another person. It seems the general attitude of the other customers towards me is one of polite detachment: they are happy to be courteous, but don't necessarily want to talk extensively.

Coffee in hand, I walk back to my car, and follow yet another semi-truck down the street toward my next turn. I once again dodge potholes, slowing for the semi-trucks that pull off into various parking lots and gas stations. I am again struck by the amount of grey there is as I drive over my first set of railroad tracks. On either side of me, tall grey walls form industrial buildings that from the outside appear to be empty.

Finally, at my second-to-last turn, I drive over another set of railroad tracks and past a place that buys scrap metal. There, I carefully maneuver my way between two trucks full of random bits of metal and bedsprings, before I cross three more sets of railroad tracks. The street I take to arrive at work runs alongside the metro line, and the streets that branch off are mostly empty. One street occasionally has large piles of clothes, toys, cardboard, and other objects, with large blue tarps draped across above the sidewalk. Only once did I see people there: a man and a woman. The woman pushed a cart with more items as the man appeared to talk to her, though I could not hear what they were saying. I finally make my turn into the school area, noticing that in the rain, the vines that once covered a nearby building have fallen onto the sidewalk. The buildings here are grey as well, and I park in the gated school parking lot.

Down the street from the school, the buildings become largely residential. It is on these neighboring streets that the majority of my students live. The houses here are fairly small and appear old. Some of them are cleaner than others. A few look as though they might fall over, parts of them leaning sideways or having already fallen off. There is some plant growth at some houses, but for the most part, all available space is concrete and used for parking. Dogs with matted fur roam the streets, and I am always careful when I drive in the area in the dark because 
there are many cats that dart around. The students I have spoken to have all been completely unflustered by the fairly frequent presence of deceased animals in the street or on the sidewalk as they walk to or from school.

The zip code area where my school is located covers approximately 4.29 square miles of land and has a population of 102,926 (“90011 Zip Code," 2019). Also according to usa.com, the population is largely Hispanic, $90.43 \%$ of the total population. Broken down further, $79.04 \%$ of that population is Mexican, with general Central American as the next-largest demographic. The area is almost an even split between men and women, and most people are between the ages of 25 and 34 years old. In the area, $64.63 \%$ of the population has less than a high school education, though current school enrollment is at roughly $98 \%$. Most of the people living in the area are families, with some two-person households. $51.63 \%$ of the population is native to the United States, while $39.73 \%$ of the remaining population is foreign born without United States citizenship. Spanish is by far the most commonly spoken language, with $84.08 \%$ of people speaking it. Most of the population is in the labor industry, and the per capita income is far lower than the state or national average at $\$ 9,350$ as opposed to $\$ 29,906$ (state) or $\$ 29,889$ (national) (“90011 Zipcode," 2019). According to usa.com, 44.17\% of the population in this zip code is in poverty. Most of my students' families rent the houses in the area, only a few families own the house they live in, and those that do have owned it for a number of years.

The neighborhood began as a predominantly African-American population, but today is mostly Spanish and English-speaking, with the Eastern and Southern areas being primarily of Latinx descent ("Los Angeles Almanac," 1998). Other areas in the city speak primarily English. The city began to truly grow toward its present-day size in the 1950 s reaching a population of almost 2 million in 1950 and then increasing from there ("Los Angeles Almanac," 1998). The 
population remained fairly steady at just under 3 million before jumping significantly to almost 3.5 million in the $1990 \mathrm{~s}$.

Blakesburg as a whole boasts many different industries, everything from high-end businesses to labor companies. The area around my school is almost entirely industrial, with a few warehouses and restaurant chains scattered among the warehouses. Most of my students' families work in the area: typically, the male guardians work either as laborers or mechanics, while the female guardians are involved in child care businesses or retail jobs. The fashion district is quite close to the school, and so there are many wholesale clothing stores or warehouses on the surrounding streets.

The most important resource for my students and their families is after school care for the children who are too young to be on their own. Many of my students' guardians work long hours that prevent them from being available to care for their children in the afternoons, and so they rely heavily on after school programming. The school offers one such opportunity, ARC, which allows the students to choose an interest or club to belong to. The organization will then plan activities for the students. For example, earlier this year, the science club was able to visit the local science museum. A similar local resource, but one that is not school-funded, is A Place Called Home. The organization, located just a couple blocks from my school site, offers “...a safe, nurturing environment with proven programs in arts, education and wellness for the young people..." (“A Place Called Home,” 2019). A small bus stops outside the school each day to pick up students who are attending classes at A Place Called Home, because though the walk would be short, it is one that some parents are uncomfortable with due to potential dangers in the area. According to neighborhoodscout.com and crimereports.com (with data supplied by the local police department), the area around the school is one of the most dangerous in the city. My 
students have experienced this first-hand, as have I to a decidedly lesser extent. At the beginning of the year, a car belonging to one of the administrators was broken into. In half a school year, we have had four lockdowns due to police or gang activity in the surrounding area. I once asked a class of 30 of my $6^{\text {th }}$ graders about violence they had seen in their neighborhood, and 24 of them had either witnessed or heard a shooting occur.

While the community has had challenges in the form of crime, almost no green space, and low-income living for the past 50 years, it also has developed many assets to combat those challenges. The staff at the school and the students and families associated with it are all closelyknit. Families attending the school are frequently related: many of my students are cousins by blood. Those that are not officially related are often so emotionally close, and the families spend so much time together, that they become as involved in each other's lives as blood relations. While there are no nearby community centers other than A Place Called Home, the families create their own community space in their homes, at parks that can be accessed by car, and at the school itself.

\section{Community Events \& Community Members}

The community events in the area are almost entirely either private family parties (birthday, holiday, etc.) or they are events hosted by the school. I was unable to go to any student birthday parties (though I was invited) as it is not allowed by the school. However, I was able to hear about these events and I attended many of the school events that provide families with a sense of community that the neighborhood itself lacks. According to my student Maria, parties held by families involve “... a lot, a lot, a lot of food. And a lot of music.” (M. Rosas, Personal Communication, 2019). The other students I spoke to offered similar comments, adding that sometimes there would be friendly games of soccer played as well if the party was held at a park. 
Because the neighborhood is not conducive to community activity beyond small to midsized gatherings, the school hosts quite a few opportunities for students and families to mingle. First, I attended the school's Harvest Festival, held so that students and their younger siblings could enjoy trick-or-treating and small party games in a safe environment. The students led their parents and younger siblings (all of whom were dressed to impress in their very best costumes) through the darkened hallways of the school, gathering candy from teachers who had decorated their rooms to ensure the correct "spooky" vibe. The parents I spoke to were extremely grateful for the opportunity to enjoy time with their children as a community. As Gabriella Flores told me, they "...don't get to do this without the school. Is [sic] too much dangerous [sic] for walking at night with the kids." (G. Flores, Personal Communication, 2019). Gabriella has two children, one a $6^{\text {th }}$ grader, and the other only 5; a small boy dressed as Batman who grinned up at me as I taught him how to say "trick-or-treat" and then receive candy. In addition to attending school festivals, I have now chaperoned two dances. These dances are ideal for our students, giving them a chance to socialize with each other when they might normally be unable to due to distance, lack of transportation, and safety concerns.

The only community members I was able to speak to who would offer insight into the community were the students and their parents. The majority of the other people that I was able to speak to are from outside the area, just there to work at a local restaurant or coffee shop. I was never able to find anyone working in the local industrial buildings or scrap metal yards who could or would communicate with me, and with no community events other than those hosted by the school, my sources of information were few and far between. I was able to speak to some of my $6^{\text {th }}$ graders, $7^{\text {th }}$ graders, and their parents, however. Mother Hannah Corral stressed that even though the area was a "bad" one, it also had "...lot of friends, we [sic] like family here, even 
though we [sic] not really" (H. Corral, Personal Communication, 2019). Her son, Richard, stated that even though he sometimes gets frustrated "with the trash and stuff," he loves the neighborhood because he gets to be with his friends and go to school nearby (R. Corral, Personal Communication, 2019). Overall, the response I got from speaking to those who live in the community was that while the area certainly has challenges, there is a large feeling of family between those who are associated with the school.

The school does not have many partnerships in the area, as there are not many organizations or businesses nearby that might offer benefits. As I mentioned briefly, the school does have staff for the after-school program run by ARC, and there is a looser partnership with A Place Called Home, as the school coordinates for transportation to the building where that program is located. Aside from those two organizations, the only other entities the school is associated with are charity organizations that the kids occasionally "adopt" families from to complete Advisory-based service projects. I believe that if there were more opportunities for partnerships or collaboration in the area, the school would make use of them, but due to the largely industrial and residential nature of the neighborhood, those opportunities simply do not exist.

The community has some after-school program services, and there is a local food bank. Beyond those two items, however, services in the community are extremely limited with the exception of those offered by the school itself. There are no libraries or museums nearby, and there are also no more traditional community centers where students and their families could interact. This is why my school puts so much effort into creating events and engendering a sense of community in students and families. I believe that if my students had access to a library (not just the ones each teacher tries to have in the classroom) or a museum, they would absolutely 
make use of them. As it is, the students occasionally will be able to go to a nearby park, and almost all of them utilize one after school program or the other.

\section{School Site Research}

Adams Middle School is located near the metro line in Blakesburg. It is on a quiet side street, trafficked almost exclusively by parents, students, and school staff. On one side of the street, a gated parking lot serves the teachers of both Adams and its co-located high school counterpart, Emerson High School. Teachers and staff have to continually be in contact, as the parking spaces are two deep, and teachers parked on the inside row cannot leave without the outside row moving. On the other side of the street, the school building looks almost identical to all of the surrounding industrial buildings; in fact, before becoming a school, the building was a clothing warehouse similar to some of the buildings that still surround it. The only difference between the school and those other buildings is that the school has a tall fence surrounding it and banners displaying the school's name posted on the outer wall.

Walking through the gate and onto school grounds, there are two things I notice first. One, the very tall flight of stairs leading to the high school level (high school classrooms are located above those of the middle school) and two, the rows of picnic tables shaded by tent tops. Inside Adams' doors, there is a somewhat open concept area in which the main office is located. From this area, the hallway narrows considerably, with classrooms and the bathrooms lining either side. On the walls, bulletin boards are covered in bright paper and decorated in frequentlychanging displays by Student Council members to reflect current events and pictures from past field trips and dances. Where there are no bulletin boards, paper posters are taped to the walls, mostly advertising for upcoming and short-lived opportunities for fun (e.g.: dances, dodgeball tournaments, food for sale, fundraisers, etc.). On the floor, there is a yellow line bisecting the 
concrete hallway, with colored arrows on either side showing students in which direction they should be walking on either side of the hall.

The campus layout has many challenges with only a few benefits. First, the narrow hallways make passing period a particularly dangerous and chaotic time. Teachers must stand at their doors to ensure no fighting or pushing breaks out as 500 middle schoolers all attempt to go to their next class at the same time. Shouts of the upcoming period number, "stay to the right" and "don't run" bounce off the walls, adding to the cacophony. For lunch, the student body must be split in half because the outdoor space is extremely limited for the students to eat. The high school has priority access to the gymnasium, so middle school students do not take any kind of physical education class. The classrooms are largely good-sized, with plenty of space for the desks and chairs of every student. The benefit to the small size of the school is that it can be fairly easy to navigate. There is not a maze of hallways, it is just one large circle. The other benefit to this layout is that the office is able to easily keep watch over whoever comes into the school, as there is not much space for slipping by unnoticed.

The school's reputation in the community is largely a good one. Families and students like the school enough to recommend it to relatives and friends, and the school is known for being safer and providing a better education than the other schools in the area. As one of my students, Alexandra Sanchez, put it, "Miss, Washington (Middle School) is where you go to get beat up" (A. Sanchez, Personal Communication, 2019). There is tension between Adams Middle School and the surrounding traditional public schools. The political climate recently has shifted even further toward distrust of charter schools and how they are run and funded, aided by a general feeling of dissatisfaction with the performance of traditional public schools from the teachers and community members associated with them. A recent teacher's strike in the public- 
school district created an even larger rift between the two educational organizations. However, our students and parents remain very supportive of the school and its practices and policies.

At Adams Middle School, there are rules and policies, but they are fairly lax in many ways, which can make it difficult to ensure students take them seriously. For example, there are policies against cell phones, drugs, fighting, etc. like a typical school, but breaking these rules results in little more than a proverbial slap on the wrist. A cell phone being used during the school day will be held in the office for the parent or guardian to pick it up at the end of the day, but there is no further punishment no matter how many times this happens. Students who are fighting or caught with drugs will have to undergo more intensive "punishments," but this is usually just in the form of detention and in-school suspension. If a student is struggling to obey these rules even then, they are given a contract to sign with an action plan that they must follow to try and avoid future transgressions. However, when a student refuses to follow the contract or breaks it, there is no further action. When discussing this topic in relation to one student in particular, my coworkers, some of whom have been at the school for nearly 10 years, all believe that they have never known a student to get expelled. As one coworker put it, "I don't think admin even knows the process" (A. Bertran, Personal Communication, 2019). While there are policies in place and some repercussions for not adhering to said policies, ultimately, there is a lack of follow-through if a student continues to break the rules.

I have witnessed this lack of follow-through in other areas as well. The general discipline process at the school is one of merits and demerits. According to the policy, if a student has received two demerits and three warnings during the same class period for the same infraction, he or she is sent to the office. In the office, the student fills out a reflection form, the parent or guardian is contacted, and then the student is escorted back to class by a campus security officer 
or administrator who can monitor the student's behavior for at least 10-15 minutes. It is rare that the second half of that policy is enforced. Instead, when a student is sent to the office, he or she frequently will just end up roaming the hallways and getting into trouble. Eventually those students might be found and sent back to class, but they will not have an escort to ensure they are back on task in the classroom. According to Michael Linsin in his article "How to be Consistent with Classroom Management," if rules and consequences are not always enforced, “...behavior, respect, and kindness take a nosedive" (2012). The lack of office support when students misbehave makes it difficult for students to take classroom rules seriously. If there are almost never consequences when sent to the office, that outcome loses power and students feel entitled to behave however they want. Teachers therefore take the responsibility for calling parents for either positive or negative reinforcement of behavior and are typically the main point of contact for families.

It is my belief that some of the difficulty surrounding discipline at the school comes from the public-school system my charter school is partnered with. At the beginning of the year, when discussing these new policies and consequences, the principal at Adams Middle School commented that "We have to change our discipline system. The district looked at it last year and said 'oh you have too many kids out of school for suspension. It's too punitive' so, this year, we're going to try and be more restorative" (J. Martinez, Personal Communication, 2019). I am a firm believer in restorative justice, but if the system is not well-organized and completely thought through, the students end up not experiencing consequences for bad behavior. The discipline procedures have changed at least four times already this year, and each time they are changed, it seems as though no attempt is made to follow the new guidelines before a different system is introduced. It has ended up being confusing for teachers and students, and frequently 
misbehavior is just ignored by the administration instead of being addressed with consequences. The administration has acknowledged that the systems they are developing aren't working as well as ones they were able to use the year before, but with the district insisting our charter schools change our policies, we are forced to keep trying to find new processes.

Technology also presents a large problem at the school. While teachers are supplied with basic computer, projector, and document camera, there is little to no training on how to utilize these resources. The gradebook is online, but once again, there is no official training on how to use it. Computers are not one-to-one, so some classes rarely get access to technology for the students to use. Cellphones are not allowed at any time, and so cannot even be used for educational purposes. The lack of technology is a frustration felt by many at the school site.

Despite the difficulties faced by school staff and students, morale is quite high. Overall, students enjoy attending school at Adams Middle School, due in part to the enormous number of school spirit related activities. For example, competitions, sports played between grade levels, assemblies, fundraisers, dances, and "Fun Fridays" where students can play video games, watch movies, and eat together for free on campus. For the most part the staff does work quite hard and enjoys doing it. The teachers are similarly content, with the majority of the faculty staying at this school site for more than five years. There is a general feeling of family at the school, and teachers interact with each other as friends, not simply coworkers. There are once-monthly staff outings, biannual retreats, and competitions and food are frequent at personal development meetings. The staff is tightly-knit, just as it seems most groups of people in this community are, and those that I have worked closely with have all been incredibly dedicated to educating students and providing them with the best experience possible. 
Along with this desire to ensure all students are supported, the school makes an effort to address the needs of all subgroups on campus, with varying success. English Learners have not only a general integrated English class, but also an ELD specific class that will help with language acquisition. An article by Mike Neer (2017) describes the benefit of having both designated and integrated classes for EL students, saying "These are the left and right hand of ELD instruction because you can't have one without the other. Every school needs both because every EL student needs both." In addition to this intensive aid for ELs in the classroom, there is an EL lead on campus dedicated to running PDs in which teachers can learn strategies to help these students. The school frequently searches for ways to bolster these students' education; for example, books were purchased recently that are targeted specifically toward EL students as they are challenging but also more approachable. Students with special needs are similarly supported. In addition to their core integrated classes, they have academic success classes which can give them more individual time and attention. For those students on campus who are LGBTQ or have had significant life experiences, the school's counseling office is fully staffed with two full counselors and another two aids. Students are always welcome to make use of those services, whether it is in class or outside of it. There is no GSA (gay-straight alliance) on campus however, and it might be beneficial for one to be started, even if the main purpose of it is to educate the students on LGBTQ issues.

Possibly our least-supported group is our gifted students. There are no GATE services on campus, and it is up to individual teachers to extend lessons to challenge these students. The closest thing the school offers is the advanced "elective" version of English or math. For example, $6^{\text {th }}$ graders with a higher than average lexile will take Drama in addition to the traditional core English class instead of the remedial Read 180. High achieving math students 
take Technology in addition to their general math class instead of Math Foundations. Beyond these separate classes, the only other service offered to GATE students is the opportunity to apply to the local community college and take Saturday or summer courses to bolster their education. The Adams Middle School college counselors help with these applications, but it is still not truly a school service.

\section{School Mission \& Demographics}

Adams Middle School has adopted the same mission carried by the general charter organization to which it belongs. In multiple places on its website, the school proudly declares that its "...mission is to help transform public education so ALL students graduate prepared for college, leadership and life" (“Animo Jefferson Charter”). This has been the organization's vision ever since it was founded in 1999. Each school that has been opened since has carried the same ideals. At Adams Middle School, the mission statement is proudly displayed on posters throughout the school and is frequently discussed in professional development meetings and workshops. The school's "theme" to guide staff this year is "Grow, Push, Serve" which works to guide educators to both grow themselves and aid in student growth, to push for new and better work, and to always remember to serve the students and community around us. The school's personal vision for this year was developed by administration and is a common talking point alongside the idea of preparing students for college, leadership and life.

The student body at Adams Middle School is 99\% Hispanic, and almost all of the remaining 1\% is African American ("Great Schools: Animo Jefferson"). Most of the students speak some Spanish, but their actual level of Spanish comprehension varies greatly, with some students only able to engage in basic conversational level Spanish. In general, more students are able to speak Spanish than are able to read or write it based on a general poll of my classes. 
Students range in age from 10 to 14 , grades 6-8. There are roughly 550 students at the school, with about $25 \%$ of those learning the basics of English ("Great Schools: Animo Jefferson").

The school faculty is fairly diverse. Of the 25 teachers at the school, roughly ten of them are white, another ten are Hispanic, two are African American, and three are of Asian descent. Most of the teachers are female, though the percentage is probably roughly 60-40, so there are quite a few male teachers at the school. Most of the teachers speak more than one language, with the second language most-often being Spanish. The teachers range in age from mid-twenties to mid-thirties, with a couple in their forties, but no older. The office staff are all women in their forties, all of them Spanish speakers of Hispanic descent. The two counselors are both Spanishspeaking women in their forties. There are three campus security officers, two of whom are male, one of whom is female. All three speak Spanish and range in age from lower to mid-thirties.

The administration at Adams Middle School consists of one principal and two vice principals. The principal is male and speaks Spanish. He is in his mid-forties. Of the two vice principals, one is male and the other female. They both speak Spanish and are in their midthirties. All three administrators are of Hispanic descent.

Many of our students attend the high school that is located on the same campus as the middle school, though some do apply to local magnet schools and attend there instead. It is very rare for students to go to the general public high school nearby as it has a reputation for being extremely dangerous with quite a bit of gang activity, according Laura Green, one of my coworkers who has served the community as a teacher for many years (L. Green, Personal Communication, 2019).

The students who thrive on campus are those that can largely self-monitor their behavior. Students who struggle with self-discipline have a more difficult time being a successful student. 
In my opinion this is because the school overall lacks the necessary follow-through with consequences that I discussed earlier. Students who are able to manage their own behavior or only need a minor amount of guidance from the teacher will succeed academically, but those students who need more guidance and more structure struggle because of the lack of structure throughout the school. While teachers might have procedures in place in their classrooms, these practices are not universal. There is no procedure for students traveling from one class to another, no grouping method to ensure safe and not chaotic maneuvering, and after school, the ARC program has extreme difficulty keeping control of the students they are supposed to be monitoring. The program uses my classroom after school and consistently I come into my room to find items, desks, and chairs misplaced or damaged. Many teachers have complained that the program allows students to run wild with a lack of clear rules, but nothing has truly been done to rectify the situation. Overall, students who need discipline and clear procedures imposed upon them because they cannot self-regulate are negatively impacted by the school's lack of consistent rules and consequences.

Where the school excels, however, is in its parent involvement. Teachers are encouraged to contact parents if problems with a student arise, and there is a Parent Coordinator who works part-time in the office to assist at times if necessary. If students are struggling quite a bit, parents will be called in for meetings with all the teachers that particular student has, and the followthrough on the parent's end is typically fairly consistent. Parents will even come to school with their child (if their work schedule allows) and will sit next to their student in classes for a day. This usually is embarrassing for the student and works for at least a bit of time to ensure they behave the way they are expected to. Parents are also very involved in office work. Parent volunteers are frequently called in to stuff envelopes and do other small tasks around the school 
and are usually quite happy to do so. Many parents attend Back to School Night and other school festivals and functions. In general, the parents and guardians of the students like to be included in their child's education, and the school feels like more of a large family unit because of it.

\section{Classroom Exploration}

One of the things I have struggled with the most on my journey as an educator is the look of my classroom. I have never been the kind of person who hangs things on the walls; from when I was young, through high school, college, and beyond, where most people would have pictures or posters on the walls, I left them blank and white. I personally find that empty space relaxing, but to many people, and to many of my students, that emptiness feels clinical and cold. Throughout the year I have put in an effort to attempt to make my classroom as warm and welcoming-looking as possible, because I want my students to feel comfortable in the space. Learning is infinitely easier when there is some level of relaxation achieved. According to Joan Young in "Encouragement in the Classroom," the "Classroom environment is one of the most important factors affecting student learning. Simply put, students learn better when they view the learning environment as positive and supportive" (2014).

I have had a much easier time creating a good feel for my classroom in terms of my interactions with students. Each day, I stand at my door during passing period, greeting students as they walk by, often offering handshakes, fist bumps, high fives, or even hugs to those students that seek out some sort of physical hello as opposed to just the verbal one. I made an effort to know not only my students' names, but also the names of their friends who I might not even have in class. In the classroom, I always attempt to find at least some small part of a student's answer that is correct and praise them for their work. I am ready and able to listen to their ideas and their struggles without judgment, and as a result, I have many students coming by my room during my 
free period and before school just to say hello and chat. I open my door in the morning so students can have a place to gather before school starts, where they can talk and laugh together with me to still watch over them and make sure nothing is getting out of hand. When I speak to my students, I largely try to treat them as equals if possible. This does not apply in situations of discipline, but in general conversation, I want to make sure my students feel seen and heard by me, that I recognize them as people, and that I hope they see me as a person as well, not just a figurehead. I've been quite successful in this regard. I have acted as a sort of mentor or secondary counselor to some of my students, helping them with school stress and minor relationship trouble when they need it.

I have tried to take that success in the emotional connection to my students and apply it to my decorating of the room. The after-school program makes decorating more difficult because there are restrictions on what can be left out in the room (or it will get taken or destroyed). I have, however, managed to hang some posters of my favorite shows and movies (Bob Ross, $\underline{\text { Star }}$ $\underline{\text { Wars, }}$ and Stranger Things, to name a few) and I have an ever-growing wall of student art displayed for visitors and regular class members alike. These small additions of my personality and what I enjoy to the room make it easier for students to start conversations with me, as they can ask about the posters and art in the room. It also makes the room feel more comfortable for them, and less like a cold, empty classroom.

I believe that the emotional environment I've created in the classroom is very directly tied to my teaching philosophy. My strongest and longest-held belief is that all students, regardless of age or background, are capable of great thought. What they need is a place that is accepting and welcoming enough that it is safe to fail sometimes and perhaps even expected. It is my philosophy that a $7^{\text {th }}$ grader is able to think on the same level as a $12^{\text {th }}$ grader or even beyond, 
they simply need a bit more help, belief, and expectation to get there. If I continually talk down to my students or treat them as though they are not capable of reaching these levels of higher thinking, then they have no reason to even try. I attempt to do the opposite in every interaction I have with a student. I am always looking to challenge their thinking, to push for more, and throughout it all, treat them as I would an academic equal in many ways. If they feel they have a safety net to catch them, if they feel they are supported by me, they will attempt those rigorous assignments and literary questions. That belief has been the basis for how I have interacted with students all year. I treat them with respect, talk to them as though they are people, my scholarly equals, and many of them have risen to that occasion. Students who are typically timid in class have begun to share extraordinary thinking because they feel safe doing so. The true student lives in the mind, not necessarily on the worksheet. In order to get my students to show me their minds on paper, I must first get them to be comfortable and to not guard so closely their every idea.

It is in that realm of comfort and expectation of greatness that I also highlight my students' assets and funds of knowledge. In knowing what my students enjoy and appreciate in literature, I am able to better tailor my lessons to showcasing their abilities, offering alternative ways of completing assignments where possible. I am able to engage students in lessons because I know what interests them and for how long they are able to focus before needing a new activity. Because my students feel comfortable in my class, they are more likely to share with me the things they enjoy doing. Students feel comfortable showing me both their strengths and their weaknesses, and as such I am able to emphasize the strengths they have in the work I create for them while maintaining high expectations for improvement in their weaknesses. Rather than getting discouraged, most of my students rise to the occasion because that is the norm in my classroom. My school's principal enjoys telling a story from when I did my demonstration lesson 
before being hired. He claims that after my lesson, as he interviewed the students I had taught, they kept saying that I "inspired" them. With a laugh, he complained that he "doesn't speak $6^{\text {th }}$ grader" and had to get help from the already-hired teachers in the room to get more details.

"They told me that you made them want to do better and learn more," he told me, and I have held that comment close to my heart and my practice ever since (J. Martinez, Personal Communication, 2019).

Furthermore, in knowing my student's assets, I have found that they are very competitive, and I have used this to help guide classroom behavior policies and reinforcement. As my students enter the room, I greet them, and then they collect a handout from the front table, go to their assigned seat, and begin working on the "do now." Midway through class, we have a brain break so that students are able to have a bit of fun and get refocused on the lesson for the second half. At the end of the class, students pass their books and handouts to the middle aisle of each arc of desks, then wait to be dismissed by me after making sure their area is clean. In the classroom, the students are expected to remain seated unless they've asked for permission to move and must raise their hands to speak or ask a question. I also require them to be respectful to each other, even in disagreements. As I say to them at the beginning of every class, we are all there to learn together, and we must be respectful and supportive. Students get electronic merits or demerits throughout the class period following the school's guidelines. I hand out merits for on-task behavior, academic language, helping others, generally good behavior. Students can then spend these merits at the student store. The procedure for misbehavior is that students are given a warning followed by a demerit, then a second warning followed by a demerit, then a third warning before being sent to the office for a phone call home and reflection before being escorted back to class to be observed. As I outlined earlier, this process often breaks down after 
the student is sent out, because the office does not always follow through on the consequences necessary. As a result, I have gotten creative in my classroom and have my own system for the most frequent cause of demerits, talking or shouting out.

For every shout out or talking out of turn, I put a tally mark on the board. At the end of the first day of this, I cut the number in half and that is the students' goal for the next class period. If they reach the goal, they are rewarded, and the goal is cut in half again. If not, they try again the next day. I have added a competitive component, with a larger prize for the class period with the lowest total at the end of each month, and the students are responding very well to it.

My classroom expectations, norms, and policies also lead directly into my effort to provide my students with social-emotional learning as well. All students have an advisory class that covers many social-emotional learning topics, but I refocus on them in the classroom as well. This is particularly important if my students begin arguing or treating each other poorly in class. My expectation is that we are all respectful and supportive of one another, and if students break that expectation, I turn it into a learning opportunity for the class in some ways. We spend a few minutes then practicing how to respectfully and academically disagree with someone. If the issue is more socially-based, I will make use of the counseling services at the school for the students to be mediated, but I also have a conversation with my class about how and why it is wrong to treat others in unkind or negative ways.

The students in my classes are almost entirely of Hispanic descent; I have one African American student. I have slightly more male students than female, but the percentages are still fairly close to even. Most of my students speak Spanish to some degree, though some are certainly more proficient than others. Two of my students speak almost no English at all, only Spanish, the others have varying degrees of English proficiency. Adams Middle School does not 
identify any students as GATE, but my $606^{\text {th }}$ graders are all in drama, which is the advanced English class. Roughly a third of my $907^{\text {th }}$ graders are in their advanced English class equivalent. None of my students have 504 Plans, but five of them have IEPs. For my GATE students, I always try to have an extension question ready for them if they finish their work early, and I always try to plan with them in mind. As Amy Azzam (2016) quotes Carol Tomlinson, “...teaching up_'a practice of first planning a lesson that's challenging for high-end learners and then differentiating for other learners..." ("Six Strategies for Challenging Gifted Learners"). I never want my students to feel completely overwhelmed, but I also want to challenge everyone in my classroom, and I try to at least sometimes plan lessons for my GATE students and then work on developing scaffolds for the rest of the class. I don't just give my GATE students more work to do, I actually try and push their thinking beyond what I asked the majority of the class for. For those students that have IEPs, I refer to the individual accommodations required by the IEP. In general, this includes preferential seating, breaks, more time for assessments, sentence starters, and graphic organizers.

My $6^{\text {th }}$ grade classes are much different than my $7^{\text {th }}$ grade ones. There are no students with IEPs or ELs in my $6^{\text {th }}$ grade classes. My $6^{\text {th }}$ graders are generally able to work for longer without complaint and complete more work in shorter periods of time, because they are the "advanced class" for their grade level. My $4^{\text {th }}$ period of $6^{\text {th }}$ graders is generally very serious and focused, while my $3^{\text {rd }}$ period is more energetic and wilder. Of my $7^{\text {th }}$ grade classes, $1^{\text {st }}$ period is the largest and best-behaved. They are able to focus and listen to each other for longer than my other two $7^{\text {th }}$ grade periods, and they complete work more easily. All but one of my IEP students are in this class, and I have many of my ELs in the period as well. My $2^{\text {nd }}$ period used to be the most difficult for me because the students in that period were frequently attempting to start fights 
with each other. They have calmed significantly this semester. My $5^{\text {th }}$ period struggles with being toward the end of the school day, so the students tend to be wilder and less willing to sit and work. I have to change the activities more frequently with them to keep them on-task.

In my classroom, resources are fairly basic. At the beginning of the year, teachers are given a projector, computer, doc cam, scissors, pack of whiteboard markers, and an eraser. There is currently a loose curriculum developed by the specialists at the organization, but in the coming years a full already-planned curriculum may be adopted. I have no teacher's aide, para-educator, or parent volunteers to help. I purchase pencils, notebooks and folders for my students if they need them. Technology is the biggest struggle in terms of resources. The school is not one-toone. Some classrooms have consistent access to technology, but those without a computer cart in the room must sign up for one long in advance or it won't be available. I believe it would be extremely helpful to have one-to-one technology in the classroom. We should be teaching our students how to use technology as part of being $21^{\text {st }}$ century learners, and thus preparing them for college, career, and life. Without consistent access to technology for my students, it is very difficult to follow the ISTE standards and ensure my students are able to be effective "digital citizens" and "global collaborators" ("ISTE Standards for Students").

Overall, Adams Middle School is a tightly-knit community that brings the students, teachers, and families together in solidarity against some of the difficulties faced by the neighborhood. The school is a safe haven for students to grow academically with the end goal of preparing them for college, leadership, and life. My classroom mirrors these same expectations, and I treat my students as much as I can as academic equals and provide them a welcoming and safe environment so they can stretch their intellect to the fullest without fear of ridicule should they fail. 


\section{Part D: Analysis of Teacher Effectiveness}

To conclude my research and data-gathering, I returned to my exploration of focus students, school, and larger community in order to evaluate the progress made over the course of the year. I gathered student work samples and compared them to those I'd kept from the beginning of the year, and also took into consideration the other non-academic goals I had set out for my students. All of this information was then used to develop an understanding of how effective I'd been as a teacher this year, and how teacher effectiveness can grow through the exploration of students' assets, needs, and backgrounds.

\section{The Whole Class Perspective}

As a class, my students are doing well. I have witnessed growth from many of them throughout this year. On the most-recent benchmark test, out of 33 students, 29 of them saw an increase in the ability to read and comprehend informational texts, some of them seeing a jump in their scores regarding those standards of as much as $20 \%$. I believe this increased comfort with informational texts is due in large part to my inclusion of a small ERWC unit that focused on this type of literature and how to make sense of it. While many students remain below grade level in their scores over all, there was growth from almost every student, which is encouraging.

On teacher-developed assessments, my students are much better at reading all directions and following them. Having been taught how to read a rubric and self-evaluate, students produce work that is aligned to the prompt roughly $88 \%$ of the time, compared to only around $50 \%$ of the time earlier in the year. Students no longer struggle to write longer essays and paragraphs, whereas two sentences were difficult for many of them at the beginning of the year. According to teacher-developed assessments and benchmark data, students are more easily able to choose and evaluate textual evidence, though they continue to struggle slightly with analyzing it thoroughly. 
Beyond academically, my students have made huge amounts of progress that cannot be quantified easily with data. Students are more aware of their work and how well they are doing, able to analyze their paragraphs and make changes to ensure they've covered the prompt given. I have also seen immense growth in student self-control and responsibility. At the beginning of the year, there was a laziness among many of my students; they wouldn't put in the work necessary to earn a good grade and showed little desire to make an effort inside or outside of class to be a positive member of the school community. Now, however, I have witnessed many students making changes in their behavior and in how they interact with their teachers and peers. Students are beginning to take ownership of their work and their grades in a way that they weren't earlier this year. I have seen a dramatic increase in the number of students coming to my designated office hours knowing what they'd like to work on in advance and truly completing the work necessary to raise their grade. My students are also better at discussion in class, interacting with each other in a respectful and academic way no matter with whom they agree or disagree. At the beginning of the year, any argument would devolve into a shouting match with no structure, but now, students take turns speaking and utilize their academic language abilities to articulate their thoughts in a way that is more mature.

I believe the growth I've seen in my students is due partly to a simple growing up, but I also think that some of the instructional practices I've utilized this year have facilitated the growth and achievement I've seen in my students. I believe the most important strategy I've used this year is simply to give the students time to practice the skills that are required of them. I incorporate reading, writing, and speaking into every lesson, so students are constantly building stamina in completing longer projects of each type. I've found ways of engaging students through literature they can relate to and enjoy so that as we drill concepts like evidence gathering 
or central idea, they are still interested in the work and willing to try their best. I've tried to always scaffold appropriately so that all of my students are supported, including English Learners and Special Education students. Throughout the entire year I have been working to find the sweet spot between work that is too difficult and work that is too easy for my students. I want them to be challenged, but I don't want them to give up because they feel as though they can't accomplish what I'm asking of them. I think I've gotten quite good at this, and it has definitely contributed to my students' ability to achieve this year, as have all the previous strategies I mentioned.

\section{The Individual Student Perspective}

Case Study 1: Yvette Rivas. Yvette Rivas, my first focus student, has had a year of ups and downs. When she completes her work, she has shown a sizeable increase in academic language ability. However, because of circumstances outside her or my control, she has struggled significantly as the year has progressed. Yvette often begins her work as she used to, but then either begins to draw or stare at the wall instead of completing it. When I am able to leverage her love of drawing and allow her to show her understanding of a topic through art, she is able to accurately complete her work, but otherwise no amount of one-on-one attention will ensure she finishes it (see figures A7 and A8). Yvette's struggle at the beginning of the year was her English learner status. She struggled to understand and apply language in the academic register. Now, she is largely successful in utilizing the language, but her struggle has shifted to be one of mental health and other concerns.

I had noticed that Yvette was fluctuating between moods and energy levels with increasing frequency, and so one day pulled her aside for a conversation about what was different. At first, she deflected with humor, the way she typically does, and I was going to let it 
go for the moment and try again another day, but then she became quite serious and told me that she had been to the doctor and was on "new medicine" (Y. Rivas, Personal Communication, 2019). I asked her what the medicine was for, and she said that she had been "hallucinating, and seeing the devil. And like, people whispering. And at night I sleepwalked for a few days, so my mom took me to the doctor" (Y. Rivas, Personal Communication, 2019). Concerned, I asked her how long she'd been on medication and if it was getting better, and she told me it had been a couple weeks (which would line up with when I started noticing a change in her behavior) and that she wasn't hallucinating anymore but that the medicine made her feel "sleepy" sometimes (Y. Rivas, Personal Communication, 2019). I believe her reaction to the medication is part of what is making it difficult for Yvette to finish any work in class or after school during office hours (which she still attends frequently).

In addition to her struggles with mental health, Yvette is currently in the preliminary stages of being given an IEP. She has continued to have difficulties with focus, and I believe has had some other issues that have led her mother to asking for an evaluation. While Yvette has not been diagnosed yet, the process of the IEP has been an additional hurdle for her in the second semester.

I set a number of goals for Yvette's continued education at the beginning of this year in the Action Plan section of her part in this essay. In those goals, she is making some progress, though there is definitely still room for her to grow. The first goal I had set out for her was that she be aware of her contributions in group work and that I hold her accountable to help with that self-awareness. I have put self-evaluation structures in place for her and assigned her different jobs for group work so that she is contributing in a variety of ways. This has been fairly successful. Yvette has shown that she is capable of participating in a number of different ways in 
group projects, though because of the issues I mentioned above she is still struggling to complete her work. My second goal for Yvette was to grow her lexile and vocabulary by providing her with tailored word banks and implementing “Juicy Sentence Protocol." While Yvette has demonstrated an increase in her academic vocabulary in discussion and makes fewer grammatical errors now than she did previously, despite my efforts to follow the action plan, her lexile level dropped from 653 at the beginning of the year to 561 at the mid-year test (see figure 1B). I believe her struggle to show her academic vocabulary gains is due to a lack of ability to focus on a standardized test rather than an actual lack of knowledge, given her success in discussion and shorter assessments. I will continue to work on these skills with Yvette in collaboration with her designated EL teacher and the EL Lead at my school site in the hope that we can help her overcome the challenges that are out of her or our control so that she is able to consistently showcase her ability.

For Yvette's social and emotional growth, I had established goals and strategies that would help her interact with more of her peers in a positive way and also not take what doesn't belong to her (a habit she had demonstrated many times at the beginning of the year through taking my pens). Through a gradual process of reminders from me and reflection, Yvette has significantly reduced the number of times a day she takes something without permission. It was never done with malice before, it simply seemed to be something she did without thinking, and now that I've continually drawn attention to it, she has broken the habit and has an easier time interacting with her peers in a way that is positive.

For Yvette, strategies that include an element of art have been the most successful by far. Drawing has been a way for me to access Yvette's knowledge and engage her in the lessons, and I think it is responsible for much of the growth that Yvette has had this year academically (see 
figures A7 and A8). The least successful strategy was the word bank for Yvette. She disliked being given a limited number of choices and preferred to select her own words overall with perhaps one or two suggestions. Yvette's vocabulary growth has been due in large part to my use of many sentence starters and discussion-based activities as Yvette loves to talk and tell stories.

While her academic growth this year has been perhaps slightly curtailed by her mental health and focus difficulties, Yvette has shown improvement in the areas I had identified as being difficult for her. As she moves on to next year, I would recommend that she continue to read as much as possible to help grow her vocabulary, have discussions about those books with a friend or relative, and continue to try and focus and not be afraid to ask for help if she needs it.

To Yvette's teachers for next school year I would say to be patient with her. She is without a doubt an intelligent student with a lot of laughter and insight to offer in the classroom, but she also is facing an increasing number of challenges. She requires a lot of steady guidance and an incorporation of what she loves (art and speaking) into the lessons in order to complete them successfully. Focus is difficult for Yvette, so I would recommend to any teacher she has in the future that activities change frequently and involve creativity to help her succeed.

Case Study 2: Daisy Sanchez. Daisy Sanchez has experienced an incredible amount of growth this year in spite of the occasional challenge. Even in the midst of her challenges, it is clear how much she has grown in terms of her social and emotional learning. One day at the end of lunch, I had an unexpected visit from her. Quietly, still looking mostly at the ground, she asked if she could talk to me for a few minutes. I said "yes," sat down with her, and waited for her to speak. After siting in slightly-uncomfortable silence for a few moments, it was as though a dam broke. Looking me in the eye, she started to tell me about how she was struggling in some of her classes, and that she didn't know what to do about it as her mother had forbidden her from 
attending office hours as Daisy had lied before about attending. Near tears, Daisy asked for my help. It was the most I'd ever heard her speak, and I was slightly taken-aback. Together we formulated a plan to get her grades up, and I communicated with her mother to ask if Daisy could attend my office hours. Because Daisy's mother had met me before at the interview for this essay, she gave her permission for Daisy to stay. The ordeal was a massive breakthrough for Daisy. Afterward, she was always able to make eye contact with me and began to have an easier time participating in class.

Daisy's progress in my class this year has also been partly due to the action plan I formulated for her at the beginning of the school year. My first goal for Daisy was that she get more comfortable participating in class and working on group projects. In order to accomplish that goal, I began by pairing Daisy with peers she was comfortable with before gradually introducing her to other students in the classroom through community builders and ice breakers. At the beginning of the year she would request to work alone for every group or partner activity, but now she is able to work with almost any student in the room successfully. She still does not necessarily enjoy working with peers, and would rather work alone, but her ability to interact with a classmate who isn't a close friend is dramatically improved.

After my support of her during a time of stress, Daisy is now able to maintain proper eye contact and volume when having academic discussions in class, be they partner or whole group, with only gentle reminders. There are times in class now that she voluntarily gives an answer, asks a question, or provides her opinion, whereas at the beginning of the year it seemed like an impossibility that she would interact so actively with her peers. While I was not able to get her the accommodation of a single earbud to limit her being overwhelmed by noises, I have been able to give Daisy short breaks when she seems like she's becoming particularly stressed out due 
to class activities by sending her on small "errands" to other places in the school. This allows her to step outside the room with a purpose and it doesn't draw attention to her.

Academically, Daisy has grown leaps and bounds as well. On the benchmark test, her informational text score went from a $22.22 \%$ correct, to a $50 \%$ correct in quarter two, to a $66.67 \%$ in quarter three (see figure $2 \mathrm{~B}$ ). While this is still a score barely meeting the grade level standard, she has certainly grown her informational text reading abilities. Most of this success is due to my attempt to more closely tie the informational texts read to the literary texts. For example, when reading an article about genetic engineering, I built the lesson around our main text, The Giver so that Daisy could draw connections between the two and develop a greater understanding of the information. Less successful was my introduction of a "wolf map" (reverse flow map) to try and give Daisy a way to determine the central idea of an informational text. Daisy struggled to choose details from the text that were truly important; often she would pull side notes from the author or other inconsequential ideas that would not help her determine the central idea. Most successful for Daisy was the creative approach to informational and literary texts (see figure 9A). In developing a story (one of her favorite things to do) around the informational texts we read, Daisy was far more successful in remembering and understanding what she'd read. Daisy was able to write a short paragraph-long story about genetic engineering based on the article we read, and then was extremely successful in explaining what we'd read and participating in a class discussion that made it clear she'd comprehended the reading.

While Daisy faced a bit of challenge from her mother's lack of trust, and while that technically was not something I could control, I was able to work around it and find a way to still support Daisy in her academic endeavors. 
As she transitions to a new academic year, I have a couple of action steps I would recommend for Daisy, and some advice for her teachers next year. First, for Daisy, I would suggest that she continue trying to interact with new people and her friends using the guidelines we have discussed and practiced this year (eye contact, volume, etc.). Second, I would tell her to continue writing creatively and reading. Both are activities she loves, and they support her academic development, as I have seen this year. To Daisy's teachers next year, my biggest advice would be to build trust with Daisy as quickly as possible and make use of her literary creativity. It was trust in me (at least to some extent) that allowed Daisy to begin making progress in her social and emotional development. Without that trust, I don't know that she would be comfortable sharing in class now. Her ability and love of reading and writing are a massive asset for Daisy in her academics. When her focus slips away from informational texts because she does not find them interesting, the tie back to the literary text or one she might write will allow her to refocus her energy. Daisy is a brilliant and creative student, and her voice is invaluable in the classroom; it is the job of the teacher to ensure Daisy's voice is heard.

Case Study 3: Jonathan Cruz. Jonathan Cruz has continued to endure life events that make school difficult for him to focus on, but he is still making progress academically and socially. Between quarter one and quarter two this year, Jonathan's score on the benchmark test went from $16.67 \%$ correct answers, to $26.09 \%$ correct (Jonathan has not taken the quarter three test yet) (see figure 3B). He is still struggling academically and is not at grade-level, but his growth has been significant, particularly in his ability to comprehend informational texts $(11.11 \%$ to $40 \%)$ (see figure $3 \mathrm{~B})$.

Following the action plan I developed at the beginning of the year for Jonathan has resulted in some success for him, and some continued struggle. First, as I have supported his 
English learner needs, I have provided Jonathan with more graphic organizers, visual representations of vocabulary, and academic language sentence starters for class participation. The academic language starters and visual vocabulary have been particularly successful in helping Jonathan improve. He now effortlessly uses academic language when engaging in discussions with partners and the whole class. He is able to express his opinion on various academic topics in a way that is respectful and clear. The visuals used for vocabulary have been helpful for Jonathan in that he needs only be reminded of the picture in order to produce the word, and after a few times remembering the word that way, he seems to assimilate the word seamlessly into his vocabulary. I have found it is essential that I check in with Jonathan frequently throughout the lesson and offer encouragement in order to motivate him to complete his work.

Encouragement not only helps Jonathan complete his work, but also helps him manage his behavior throughout class time. Small check-ins have worked wonders in getting Jonathan to keep trying even through patches of difficulty with the material, whereas at the beginning of the year he would have turned to yelling, profanity, and other disruptions of the class. In order to help him deal with his emotions, my original plan was to have Jonathan write in a journal, but this seemed to make his emotional state worse, I think because he struggles with writing so much. Instead, I have found occasional times during group work in class or outside of class time for a few minutes where I can check in with Jonathan and have him talk to me about what is happening. This taps into his love of oral storytelling and allows him to vent in a safe space. I have made frequent use of the "special mission" strategy for Jonathan, sending him on small errands to help give him a small break from the stress of the classroom environment. He usually returns from these errands much calmer and more willing to work. I believe the most successful 
strategies I used with Jonathan are the visuals to aid in vocabulary comprehension and the frequent check-ins. Least successful was the use of a journal for Jonathan to deal with his emotions, and so I altered the strategy to be oral storytelling of sorts, which played into Jonathan's assets and was more beneficial for him.

While Jonathan's growth this year socially, emotionally, and academically has been quite good, I feel as though it could have been better had he not encountered further challenges in his personal life that were outside of my control. First, his brother was officially sentenced to jail, and was incarcerated for roughly a month before being released to house arrest because the jail did not have the money or space to keep low-level offenders imprisoned. Jonathan expressed that while it's nice to have his brother home, it's also "kinda weird" because his brother is often away for his “punishment job where he don't [sic] get paid” (J. Cruz, Personal Communication, 2019). In addition to the mixed emotions surrounding the return of his brother, Jonathan's baby nephew died suddenly just after winter break. Jonathan thought of his nephew as more like a younger brother and was understandably devastated at the loss. He talked to me about it and made use of the counseling services offered by the school, but I believe that he was most helped by the knowledge that his other sister is expecting a baby boy later this year. Jonathan has told me he is saving his allowance money (when he earns it) to buy a Switch so he and his upcoming nephew will be able to play together. I was amazed and humbled by Jonathan's ability to simultaneously grieve and look forward to the future. These events certainly had an impact on Jonathan's work this year, and there was about a month where he seemed to completely give up on school. He couldn't focus, was more argumentative than usual, and refused to complete any work. With patience on my part, allowing him to speak and work through his emotions, and the news of his soon-to-be nephew, Jonathan slowly began to work again, attending office hours and working 
hard to catch up on work he neglected while he was busy working through all the emotions that came with two big events in such a short period of time (see figures 10A and 11A).

For Jonathan, as he transitions to the next academic year, my recommended action steps are first, to continue trying to complete every assignment fully in spite of difficulties he may face, and second, to start trying to write even a sentence a day about something in his life. The first goal is quite broad and difficult, but it is very necessary for Jonathan. He is very intelligent and capable of great work, but he needs to keep building the ability to work through challenge. If he doesn't immediately succeed in whatever it is he's doing, he needs to keep trying through the use of his own motivation, not relying necessarily on someone else to push him through. The second goal will hopefully result in a couple different benefits. First, I think it will become a healthy way for Jonathan to express his emotions when there isn't a teacher he can talk to. Second, it will develop his writing skills and eventually his writing stamina. It could be that for the first week Jonathan only writes one sentence, but perhaps as he discovers he has more to say, he will begin writing longer passages and develop his "writing muscle."

To Jonathan's teachers for the next school year, I would give a couple pieces of advice. First, be patient and give Jonathan plenty of encouragement. He does not act out or refuse to work because he's a bad kid or because he wants to be difficult, he does it because he is frustrated with himself or is having difficulties outside of school. Patience and encouragement eventually make him complete his work, whereas impatience or scolding will only make him retreat further into himself and refuse more strongly to work. Second, continue trying, as I have, to utilize Jonathan's ability to tell stories and his extremely grown-up view of the world. Often, he is able to easily grasp concepts or understand character emotions or motivation in literature that his peers cannot, simply because he has had so much life experience for a student so young. 
This is a heavy burden for him to bear (hence the need for encouragement and patience) but it also enables him to deeply understand the literature read in class and eventually express that understanding in a profound way.

\section{The Developing Professional Perspective}

My first year of teaching has been one of tremendous ups and downs and a truly astonishing amount of growth both for me and my students. I have had moments on my 2-hour commute home when I've been singing along to music, elated at the progress and triumph in my educational journey, and I have also had moments where I've been struggling to see the road through tears of frustration and exhaustion. I can say quite honestly that I've never worked harder in my life than I have worked this year. Equally, I have never encountered something that was as simultaneously challenging and rewarding as teaching. I feel as though I've actually taught all of my students something this year, and they have also certainly taught me.

Part of teaching, I've come to realize and love, is that the learning journey is not only embarked upon by the students. In order to be an effective educator, I think it is necessary to recognize that no matter how long you've been teaching, there is always something new a student can teach you. Whether it is a new way to teach a concept, a realization about the world around you, a way of looking at literature that you'd never considered, or something as simple as which type of pencil the students won't automatically destroy, there is a lesson in every day of teaching. While I found this frustrating at times because I'm a bit of a perfectionist, I also reveled in it.

A large part of why I wanted to be a teacher was because the act of learning in all its forms has always brought me a tremendous amount of joy. What better way to ensure I experience that joy for my whole life than to make a career out of it in teaching? I've come to 
appreciate the small victories in education. Not every day will include a massive "ah ha" moment. Not every day needs to. As my first year draws to a close, I have enjoyed reflecting on my progress, my students' progress, and the meaning of teaching as a whole.

My biggest successes this year were mostly in my interactions with students and my refusal to give up. I feel as though I have formed a bond with almost all of my students. I've counseled many of them through difficulties in their personal and home lives, I've helped them develop action plans to raise grades, and I've provided a safe place for them to be themselves. My classroom in the mornings before school begins is awash with the sound of laughter as 30-orso students chat with me and each other before the bell rings. I believe the fact that they are comfortable enough with me to spend that extra time in my classroom is absolutely beneficial to their learning from me, and thus is a sign of my successful relationships with my students.

My second biggest success in some ways goes hand-in-hand with my first one. Part of the reason why students are comfortable talking to me and willing to ask for help is that I don't give up on them. I don't hold grudges from one day to the next, and I don't ever tell a student they aren't capable of something simply because they struggled with it or another topic on a different day. Difficulty, in my classroom, is never a sign to stop trying. Indeed, I refuse to stop teaching, refuse to stop helping my students, and refuse to simply buy into the "He/she doesn't want to learn/can't learn" narrative that is sometimes so prevalent at schools. Every one of my students is capable of doing all of the work I ask of them. Some of them require different avenues of accessing that work, or require more time, or just someone to believe in them in order to be successful. As Lisa Delpit says in Multiplication is for White People, "I believe that if we are to create excellence in urban classrooms, we must do the following:...7. Create a sense of family and caring in the classroom" ("Introduction"). Students, my younger self included, place a 
significant amount of weight in how capable their teachers and parents believe them to be. It is the job of the teacher to act as a support system, a caring adult, and ultimately a family member to the student so he/she is able to feel comfortable in risking failure in the service of advancing the learning. I have embraced the fact that as an educator it is my job to make sure my students are provided with all of the things they need in order to grow their academic lives.

By far my biggest challenge this year was in classroom management, for a few different reasons. First, as a teacher new to the school, I think in semester one there was at times a tendency for the students to equate me with a substitute, not a full teacher who would continually hold them accountable. Substitute teachers consistently have a difficult time at the school in corralling students, and I think the "We have a sub" mentality bled over into my classroom because the students were unfamiliar with me. Another reason why classroom management was a difficulty was that there has been little support all year in regard to discipline from the administration. There have been many consequence ladders imposed this year to be school-wide, and each one has been abandoned before it has actually been implemented to fidelity. This has resulted in quite a bit of confusion among teachers and students and has led students to believe, at least in part, that there are no real consequences for their actions beyond a teacher-made phone call home or reprimand. As Jennifer Gonzalez writes in her "What Teachers Want You to Know: A Note to School Administrators," "...how teachers need your support with classroom management, or how much they appreciate it when you back them up with parents" (Cult of Pedagogy). Administration plays a vital role in the discipline process at school. While teachers can have great classroom management on their own, some support from administration when dealing with parents or when taking discipline further than the teacher has power can make the learning environment run much more smoothly. At Adams Middle School, there is a widespread 
difficulty with managing the classroom, even among its veteran teachers, and this is due in large part, I believe, to a lack of leadership when it comes time to move consequences upward for students.

Based on the TPE clinical evaluations, my greatest strengths were in creating engaging lessons that utilized gradual release and in interacting with my work community as a professional. I have enjoyed being able to create lessons all year, a process that relates to TPE 1 (Engaging and Supporting All Students in Learning) and TPE 3 (Understanding and Organizing Subject Matter for Student Learning). Designing lessons that lead students to deeper understanding and learning has been one of my favorite activities. On my long drive home, I reflect on the lesson taught that day and imagine what I could do with it in the future to make it even more interesting or supportive for my students. I have also been very successful in TPE 6, Developing as a Professional Educator. All year I have taken the professional development meetings and workshops very seriously, taking notes and participating actively in what is being discussed. I dress nicely for work, show up to everything on time, and am courteous in my interactions with my coworkers. In addition, I volunteer to help for student events in chaperoning for dances, which is very much appreciated by the administration and other teachers at the school.

My biggest areas of professional growth in terms of the TPEs include TPE 2 (Creating and Maintaining Effective Environments for Student Learning) and TPE 5 (Assessing Student Learning). Since the mid-year evaluation based on these TPEs, I have made great strides in my action plan toward proficiency in TPE 5. I have created rubrics for student use and taught them how to self-evaluate using these rubrics. I have not yet engaged in a large self-reflection for students based on a summative assessment, but as I embark on an upcoming benchmark test, I 
will be using those scores to create that opportunity for my students. For TPE 2, I have developed a closing routine that has dramatically affected the organization of my classroom in a positive way. I've made some progress in enhancing the aesthetic of the room, though it is still something that I struggle with and will continue to work on in the future.

I believe that the academic progress of my students so far says that I am a somewhat effective teacher, but that I definitely can and should continue to improve. My students have grown their abilities in many academic areas this year with me, but I feel as though with more experience I can have a larger impact in the future. While I would not say I was a "bad" teacher this year overall, or one who negatively impacted the students, I also believe I was not effective this year as I will be even next year. I feel as though I grew significantly as an educator from the first semester until now, so I can only imagine how much more growth and effectiveness I will gain as I continue to teach over multiple years. My overarching goal for myself is quite simple, at least on the surface: continue to learn. By that I mean that over the course of the end of this year, and the entirety of next year, and the following year, and every year until I retire and beyond, I want to keep learning and reflecting on what it means to be an effective educator. It is in that learning and reflection that I will be able to alter my lessons, change my strategies, and become as effective as I can be in the classroom. In order to help my students learn, I must not be afraid to continually keep learning. To accomplish this goal, I will continue to read books and articles about teachers, by teachers, and for teachers. I will take classes and stay up-to-date on the latest technology for the classroom. I will be open to trying new things, and I will continue, most importantly, to always believe in the abilities of my students, whoever they may be.

In revisiting the beginning of this lengthy essay, I find that my beliefs regarding how students learn are largely unchanged. I still believe in offering students choice, I support the 
teaching of how to think, not what to think, and I still feel as though exploration and discussion of literature is paramount to its instruction. Where I have changed most, I think, is in my practical knowledge of teaching. I began the year with a lot of dreams and big ideals, which I have retained even now at the end of the year. However, I have also matured and had a bit of a reality check regarding public education and its strengths and weaknesses. Going into this year, I had visions of a Dead Poet's Society-like classroom environment full of undermining the system, freedom of expression, speech, and thought, and standing on desks. Ultimately, that is largely the stuff of movies. I have now achieved a balance between that literary community that discusses freely and a realistic learning community that is able to share ideas in a more structured and sane way. My expectations of my students are as high as they were at the beginning of the year in terms of what level of thinking they should be utilizing, but I am much better able to support them in reaching those analytical heights without descending into anarchy over a difference of opinion.

After doing a significant amount of reading over the course of the year, and listening to many speakers, a few have really stood out to me and made a significant impact on my philosophy as an educator. First, reading Donald Kauchak's chapter “Education in the United States: Its Historical Roots" (2002) made me understand and appreciate how much education has changed and how much it still might have to change in the future. It is vital to the development of a better education system in the future to know what has shaped the system as it stands currently. The development of the Constitution and belief in "separation of church and state" gave rise to the current practice of education being a state-organized affair. As Kauchak puts it, "This helps us understand why standards, accountability, and the high-stakes tests, so common in today's education, currently originate at the state level" (p. 114). In reflecting on the education 
system and its benefits and flaws at the teacher or school level, there is a constant desire for me to also think about education on a greater scale. While I recognize the benefit in giving states the ability to organize education the way they see fit, I also believe there may be a better way of handling our educational system on a more federal level. It seems that in large part the states have control of the educational system (aside from basic rules and funding) simply because the federal government in the 1700 s did not know how to regulate it all. It may be time to rethink the system, and for that it is important to know why our school system functions the way it does today.

The second reading that had a significant impact on my educational philosophy this year was Marzano's Classroom Management That Works (2003). In Chapter 4, Marzano explores the effect that teacher-student relationships have on classroom management, stating: "If a teacher has a good relationship with students, then students more readily accept the rules and procedures and the disciplinary actions that follow their violations" (p. 41). This reading had a huge impact on me because while having a good relationship with my students was already something I wanted, I now was able to point to reasons why it was important along with having access to data to support my beliefs. It was not ground-breaking literature for me, but it was very validating and comforting to know that my desire to have positive interactions and relationships with my students was actually a good teaching strategy.

The final piece of reading that had the largest impact on me was Mary Flannery's "This is Your Student's Brain on Trauma" (2017). I found this reading deeply disturbing because it makes clear what a massive problem there is in terms of our young people in this country being exposed to traumatic experiences and how this can then shape their education and ultimately the rest of their life. As I've gotten to know my students, I have continually returned to this article, finding 
what it discusses in my teaching reality and looking for more information. At the beginning of the article, Flannery provides the following statistic, "The numbers are start: One in four U.S. students will witness or experience a traumatic event before the age of 4, and more than twothirds by age 16" (p. 42). This statistic, when I first read it at the start of the year, was distressing to me because it is horrible that so many young people are exposed to trauma. It became a reality when I had a conversation with a class of my $6^{\text {th }}$ graders at the mid-year mark. In exploring narrative writing and how it can make change, my class stumbled upon the topic of gun violence. I asked for a show of hands as to how many students had either heard or witnessed a shooting. In the class of thirty 11-and-12-year-olds, every student had a hand raised. This article about the impact of trauma on students and their education went from disturbing theory to a reality that I had to really come to terms with and begin dealing with to reach more of my students.

Overall this year, I have learned a lot about being an effective educator, and most of it boils down to my final point in the previous paragraph: an effective educator knows his/her students and makes a concentrated, consistent effort to reach as many of them as possible. Effective teachers make time for their students, listen to concerns and questions, and act as support systems for their students no matter who those students may be. As a teacher, I am always thinking about each of my students as I plan lessons; I know where each student will exceed expectations and where they will need increased support, and I plan accordingly. Teaching, in my opinion, is absolutely both a science and an art. It is a science in that there is data for much of the problems that occur in the classroom. Student data is used to shape future lessons, school-wide data is used to shape educational reform, research and outside publications shape what happens in the classroom to better support the students. It is an art because it is never finished. Artists in my experience are never content with their "finished" product. Without 
deadlines an artist could continue to change and shape their work for all time, making small improvements that lead to further improvements, and so on for eternity. Effective educators take both sides of teaching and utilize them in tandem. The art of teaching well is that the work is never finished. There is always one more change to make, one more aspect of the lesson that could have been better, one more student to reach and lift up through education. The science of teaching builds upon that desire for continual change and improvement in that it provides new data, new strategies, and new insight into our students and their brains and how we can better prepare them for their future.

At the close of my first year of teaching, and after reflecting on all I have learned, done, and seen, I am left thinking again about Lynette Creasy, my $11^{\text {th }}$ grade AP English teacher. Every year, with her students, Ms. Creasy would insist that we memorize a quote from Ralph Waldo Emerson's Self-Reliance:

What I must do is all that concerns me, not what people think. This rule, equally arduous in actual and intellectual life, may serve for the whole distinction between greatness and meanness. It is the harder, because you will always find those who think they know what is your duty better than you know it. It is easy in the world to live after the world's opinion; it is easy in solitude to live after our own; but the great man is he who in the midst of the crowd keeps with perfect sweetness the independence of solitude.

Ms. Creasy lived in accordance with this quote, and I have attempted to as well. It sums up, I think, what I want for my students as well. Through their education, they should learn to be self-reliant in the way that Emerson promoted. Particularly in today's world of easy global communication, with every opinion able to be shared and amplified by the internet, it is crucial that my students learn to think for themselves, but also not to do so to the exclusion of all other voices. They should act and think for themselves, use their voices to communicate with the world around them, and be their independent selves, while simultaneously being open-minded enough 
to allow for other opinions. It is my hope that in this year I have gotten them at least one step closer to this ideal of "self-reliance," as I know I have certainly made strides toward that goal this year myself.

\section{Conclusion}

The process of writing this ethnography was overall a crucial exercise, particularly in my first year of teaching. Through its creation I have learned more about my students, their families, and where they come from. Because of those new insights, I have been able to tailor my lessons and strategies to best support not only my focus students, but also the other students I have in class who may have similar assets and needs. It has shown me the full scope of the impact education can have. I ruminated on my own experiences with education, the teachers who shaped me, and the ideas and attitude I would therefore bring to my own classroom. I was then able to examine my own students' ideas, experiences, and attitudes, and then broaden that further to see how education can affect a community. In doing all of this research, I myself became a member of the community, able to form deeper connections with my students and their families. Ultimately because of the action plans I formed for this essay, my students were able to grow academically and socially in ways they might not have otherwise grown. I entered my first year knowing that being a teacher is an enormous responsibility, and the writing of this ethnography has only driven that point home even further. It has also, however, allowed me to have a space where I can fully think about education and teaching as a profession and what it means to me. It has let me organize my thoughts regarding some of my students and the unique assets and needs they all bring to the table. The ethnography has been my own education as I attempt to educate 
others this year, and it has reminded me constantly of my firm belief that education is a gift that unites us all. 


\section{References}

90011 Zip Code. (2019). Retrieved February 9, 2019, from http://www.usa.com/90011-ca.htm

Animo Jefferson Charter Middle School. (n.d.). Retrieved February 9, 2019, from

https://ca.greendot.org/jefferson/

A Place Called Home. (2019). Retrieved February 9, 2019, from https://apch.org/

Azzam, A. (2016, April). Six strategies for challenging gifted learners. Education Update, 58(4).

Retrieved February 9, 2019, from http://www.ascd.org/publications/newsletters/education-

update/apr16/vol58/num04/Six-Strategies-for-Challenging-Gifted-Learners.aspx

Bondy, E., \& Hambacher, E. (2016). Let care shine through. Educational Leadership,50-54.

Commenting on student writing. (n.d.). Retrieved May 28, 2018, from

http://teachingcenter.wustl.edu/resources/writing-assignments-feedback/commenting-on-student$\underline{\text { writing/ }}$

Cummins, J. (1979). Cognitive/academic language proficiency, linguistic interdependence, the optimum age question, and some other matters. Working Papers on Bilingualism,19, 121-129. Retrieved November 23, 2018, from https://eric.ed.gov/?id=ED184334.

Dee, A. L. (2011). Preservice teacher application of differentiated instruction. The Teacher Educator,53-70.

Delpit, L. (2014). Multiplication is for white people. Retrieved March 10, 2019.

Dewey, J. (n.d.). My pedagogic creed. Retrieved May 28, 2018 from http://dewey.pragmatism.org/creed.html

Dweck, C. (2015). Growth mindset, revisited. Education Week,35(5), 20-24. Retrieved November 23, 2018, from https://www.edweek.org/ew/articles/2015/09/23/carol-dweck-revisits-the-growth$\underline{\text { mindset.html. }}$ 
Emerson, R. W., \& Porte, J. (1983). Essays \& lectures. New York: Literary Classics of the U.S.

Explore Animo Jefferson Charter Middle School in Los Angeles, CA. (n.d.). Retrieved February 9, 2019, from https://www.greatschools.org/california/los-angeles/25214-Animo-Jefferson-Charter$\underline{\text { Middle-School/ }}$

Fisher, D., \& Frey, N. (2014). Checking for understanding. ASCD.

Fisher, D., \& Frey, N. (2011). The purposeful classroom: How to structure lessons with learning goals in mind. Alexandria, VA: ASCD.

Flannery, M. E. (2017). This is your student's brain on trauma. NEA Today, winter, 42-45.

Gallagher, K. (2014, April). Making the most of mentor texts. Educational Leadership, 71(7), 28-33. Retrieved November 4, 2018, from http://www.ascd.org/publications/educationalleadership/apr14/vol71/num07/Making-the-Most-of-Mentor-Texts.aspx

García, O., \& Kleifgen, J. A. (2010). Educating emergent bilinguals: Policies, programs, and practices for English learners. Retrieved November 4, 2018.

Gonzalez, J. (2018, September 20). What teachers want you to know: A note to school administrators. Retrieved March 10, 2019, from https://www.cultofpedagogy.com/letter-toadministrators/

ISTE standards for students. (n.d.). Retrieved February 9, 2019, from https://www.iste.org/standards/for-students

Kauchak, D. P., \& Eggen, P. D. (2014). Introduction to teaching: Becoming a professional. Boston: Pearson.

King-Sears, M. E. (2008). Facts and fallacies: Differentiation and the general education curriculum for students with special educational needs. Support for Learning,23(2), 55-62. Ladson-Billings, G. (1994). The dreamkeepers. San Francisco: Jossey-Bass Publishing Co. 
Linsin, M. (2012, June 16). How to be consistent with classroom management. Smart Classroom Management. Retrieved February 9, 2019, from https://www.smartclassroommanagement.com/2012/06/16/how-to-be-consistent-with-classroommanagement/

Los Angeles Almanac. (1998). Retrieved February 9, 2019, from http://www.laalmanac.com/ Lunenburg, F., \& Lunenburg, M. (2014). Applying multiple intelligences in the classroom: A fresh look at teaching writing. International Journal of Scholarly Academic Intellectual Diversity, 16(1).

Marzano, R. J., Marzano, J. S., \& Pickering, D. (2003). Classroom management that works: Research-based strategies for every teacher.

Neer, M. (2017, May 31). Designated and integrated. Dataworks: Educational Research. Retrieved February 9, 2019, from https://dataworks-ed.com/blog/2017/05/designated-and-integrated-eldinstruction/

Noddings, N. (2008, February). All our students thinking. Educational Leadership, 65(5), 8-13. Retrieved May 28, 2018, from http://www.ascd.org/publications/ educational-leadership/feb08/vol65/num05/All-Our-Students-Thinking.aspx

Simmons, D. N., \& Brackett, M. A. (2018). Applying an equity lens to social, emotional, and academic development (pp. 1-11, Issue brief). Pennsylvania State University.

Young, J. (2014). Encouragement in the classroom. ASCD. Retrieved February 9, 2019, from http://www.ascd.org/publications/books/sf1 14049/chapters/The-Importance-of-a-PositiveClassroom.aspx 


\section{Appendix A}

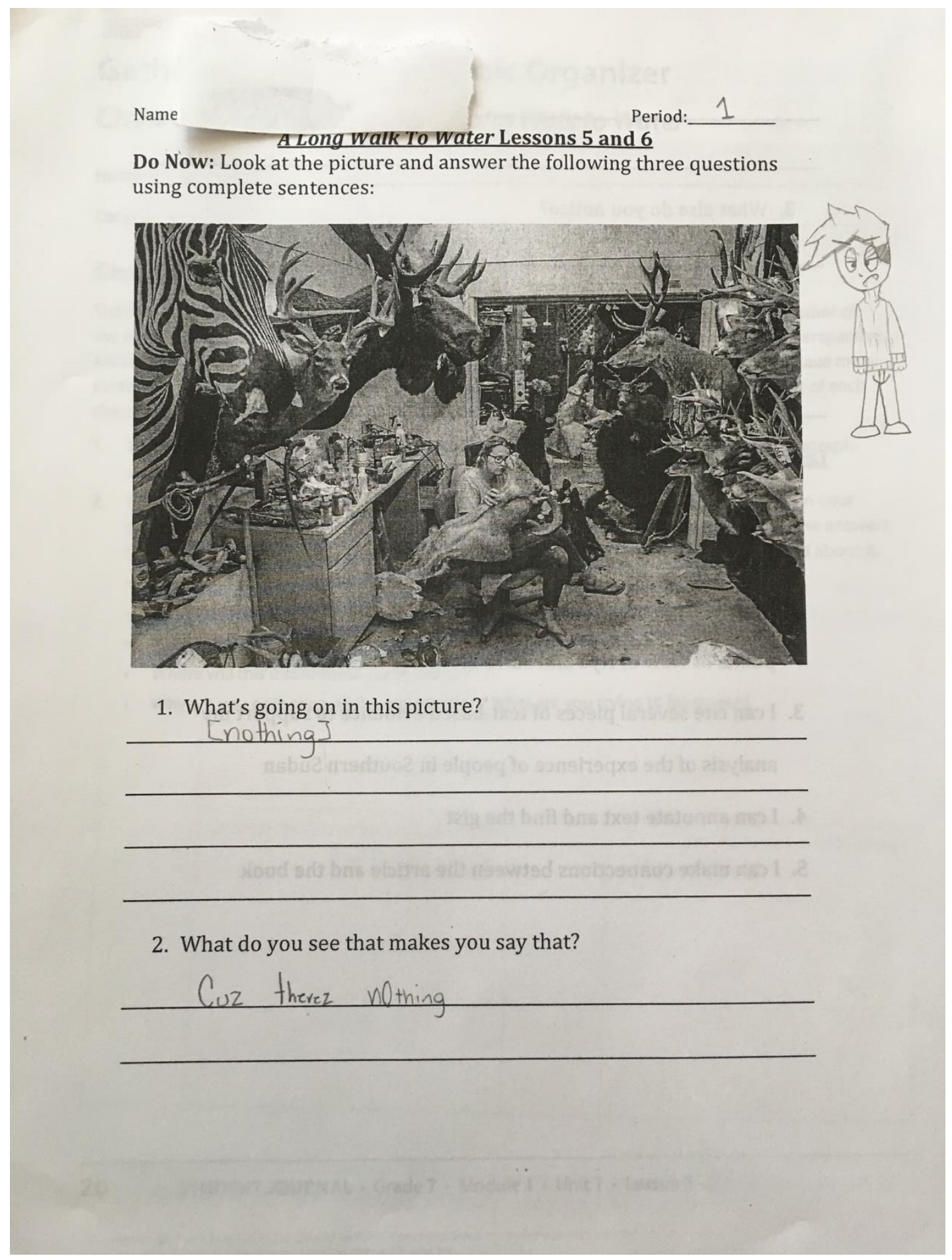

Figure 1. Y. Rivas first semester work. Little work done, struggles with spelling, unfocused drawing 


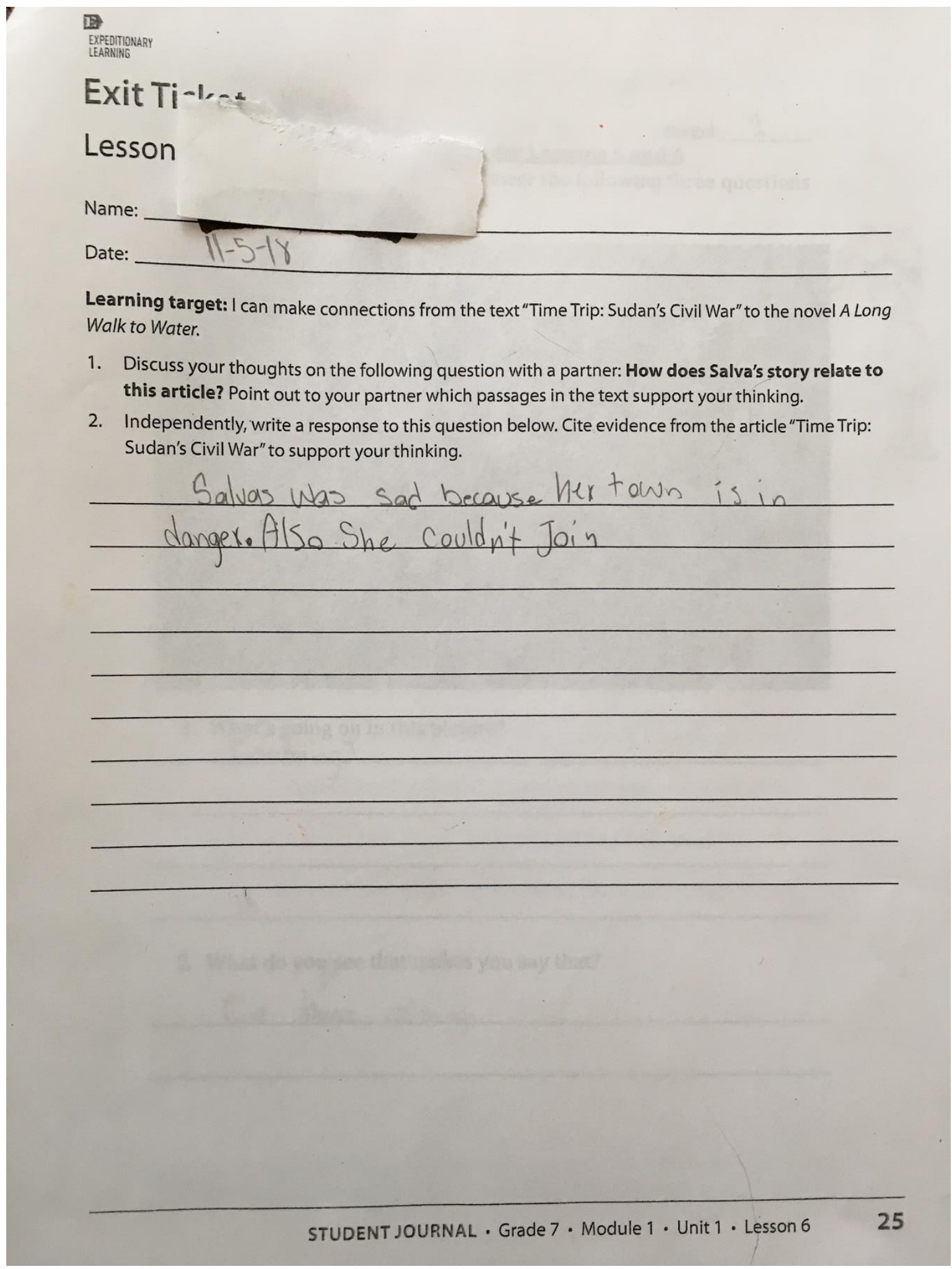

Figure 2. Y. Rivas first semester work demonstrating incomplete sentences and inattention to directions and what was read. 


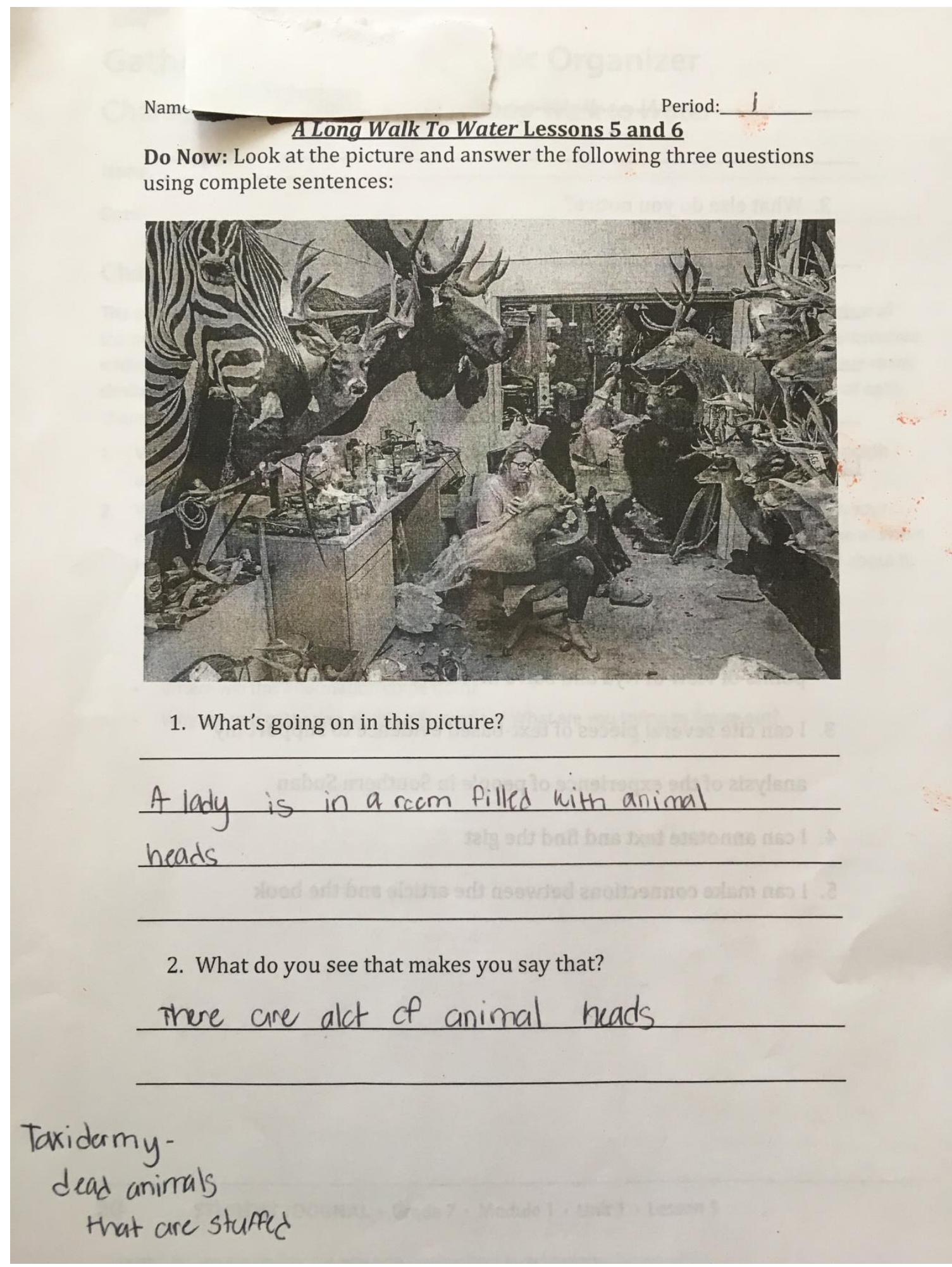

Figure 3. D. Sanchez first semester work with vocabulary she supplied for the class, demonstrating knowledge of higher-tier vocabulary. 
E.

EXPEDTINANARY

\section{Exit Ticket}

Lesson 6

Name:

Date: $11 / 5 / 18$

Learning target: I can make connections from the text "Time Trip: Sudan's Civil War" to the novel A Long Walk to Water.

1. Discuss your thoughts on the following question with a partner: How does Salva's story relate to this article? Point out to your partner which passages in the text support your thinking.

2. Independently, write a response to this question below. Cite evidence from the article "Time Trip: Sudan's Civil War" to support your thinking.

This story relates to salva's stary because he

is running awoy frem the war and fighting.

Figure 4. D. Sanchez first semester work demonstrating difficulty with informational text. She did not discuss with a partner prior to completing the assignment. 


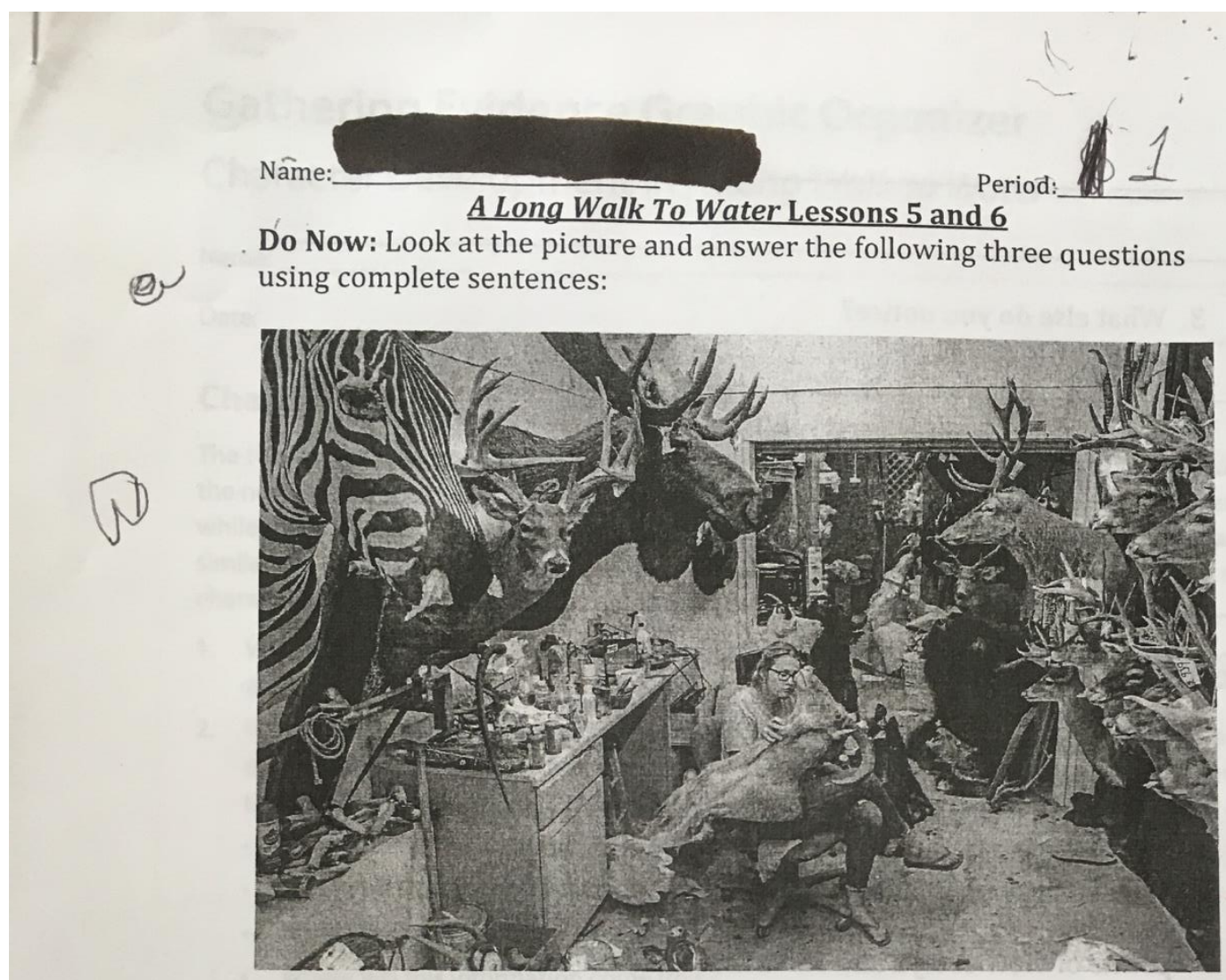

1. What's going on in this picture?

2. What do you see that makes you say that?

1

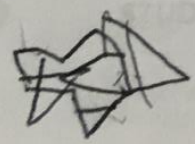

Figure 5. J. Cruz first semester incomplete work with lines drawn, focus was an issue. 
H

EXPEDIIINANARY
LEARNING

Exit Ticket

Lesson 6

Name:

Date: Learning target: I can make connections from the text "Time Trip: Sudan's Civil War" to the novel A Long
Walk to Water.

1. Discuss your thoughts on the following question with a partner: How does Salva's story relate to

this article? Point out to your partner which passages in the text support your thinking.

Sudan's Civil War" to support your thinking.

Figure 6. J. Cruz first semester work demonstrating lack of completion. 


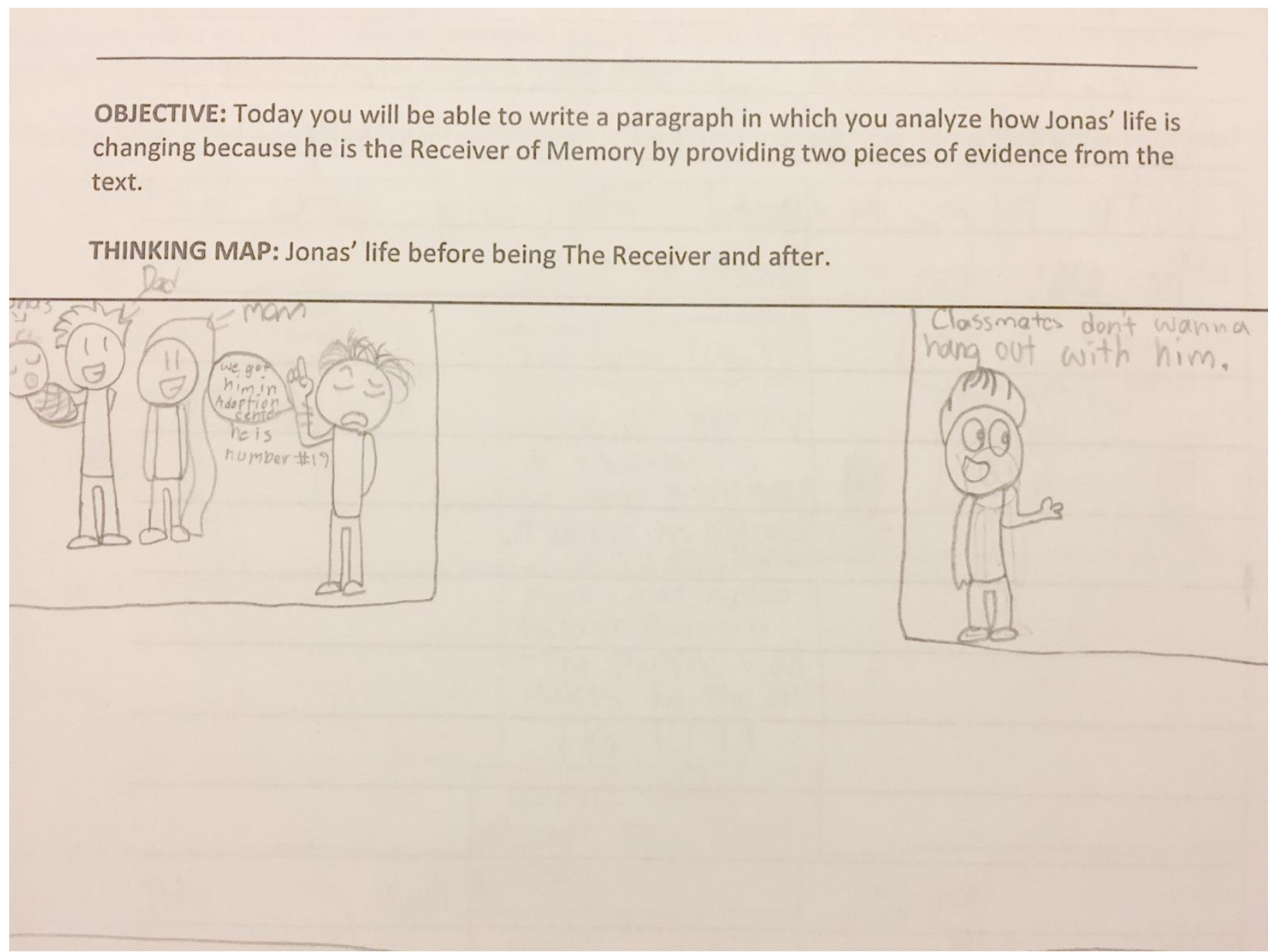

Figure 7. Y. Rivas second semester focused drawing to keep track of story plot and progress. 


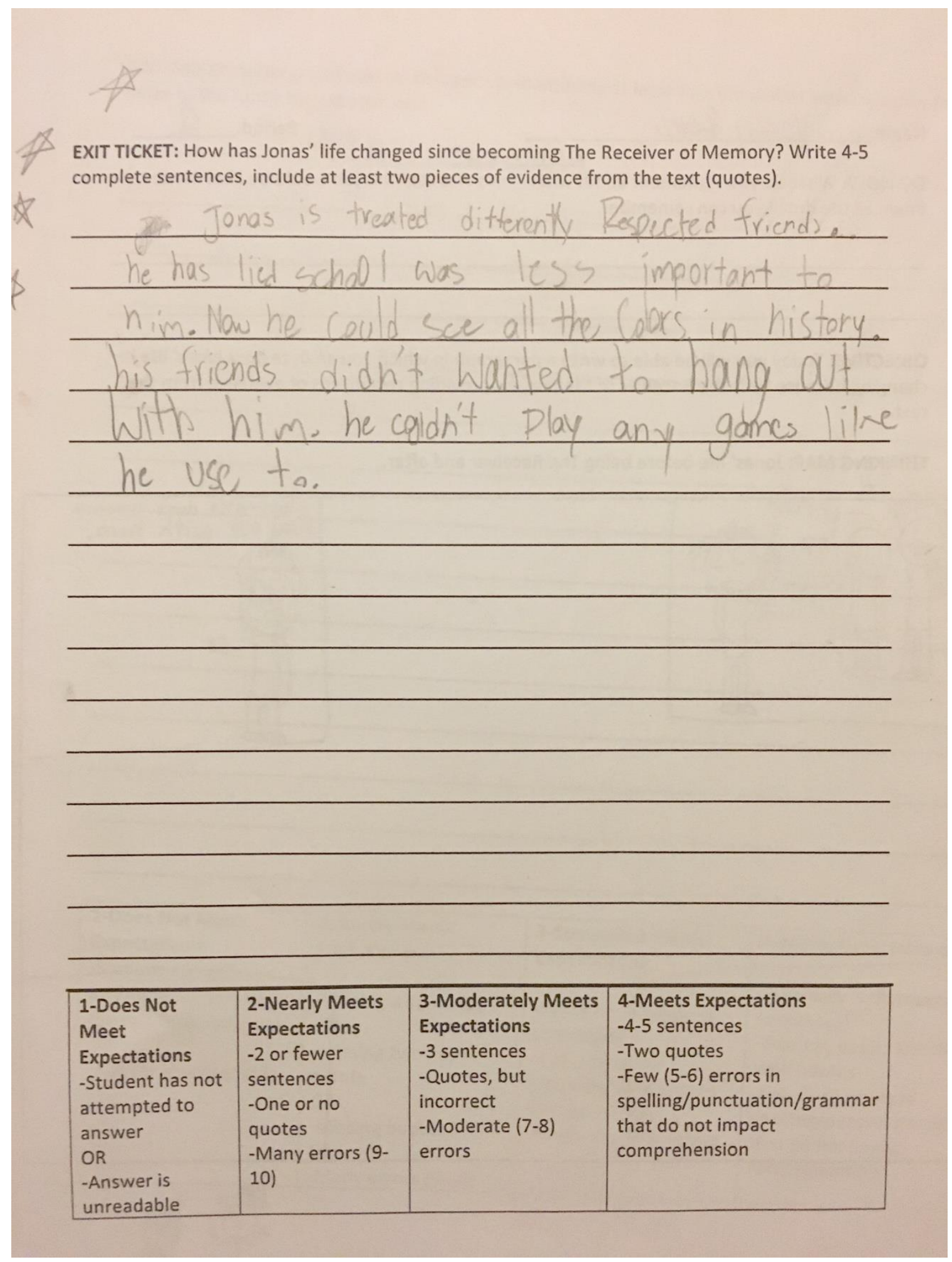

Figure 8. Y. Rivas second semester progress toward understanding plot and increased focus.

Demonstrates continued challenges of quotations and direction following. 
EXIT TICKET: How will knowing about what "release" is affect Jonas and the plot? Make at least two predictions. Use your thinking map! Write 4-5 sentences.

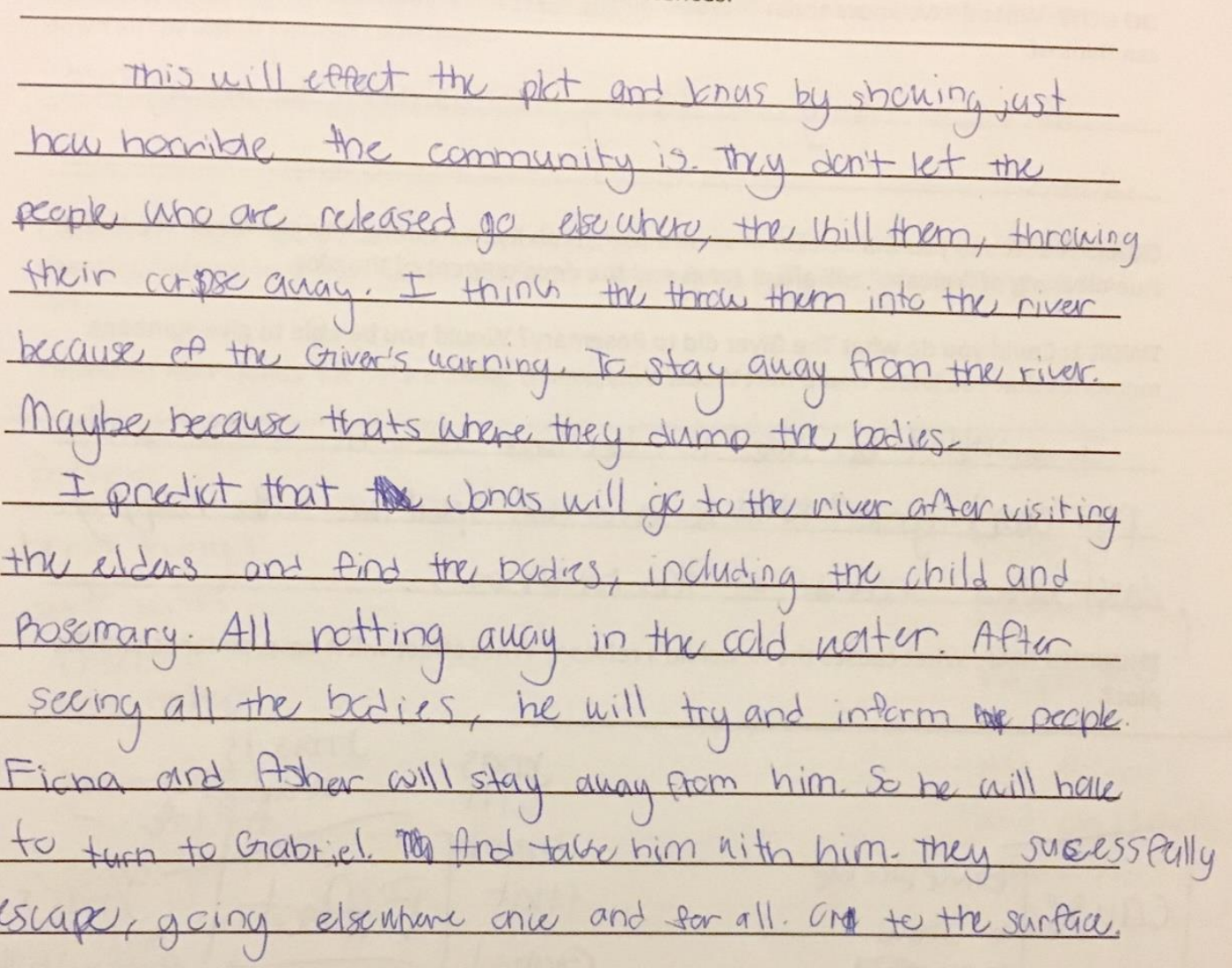

\begin{tabular}{|l|l|l|l|}
\hline 1-Does Not & 2-Nearly Meets & 3-Moderately & 4-Meets Expectations \\
Meet & Expectations & Meets & -Two logical predictions \\
Expectations & -No logical & Expectations & $-4-5$ sentences \\
-Student has not & predictions & -One logical & -Few (5-6) errors in \\
attempted to & OR & prediction & spelling/punctuation/grammar \\
answer & -2 sentences & OR & that do not impact \\
OR & - Many errors (9- & -3 sentences & comprehension \\
-Answer is & $10)$ & OR & \\
unreadable & & -Moderate (7-8) & \\
& & & \\
\end{tabular}

Figure 9. D. Sanchez second semester work demonstrating improved completion through tie to creativity. She participated successfully in a discussion with a partner before completing the work. 


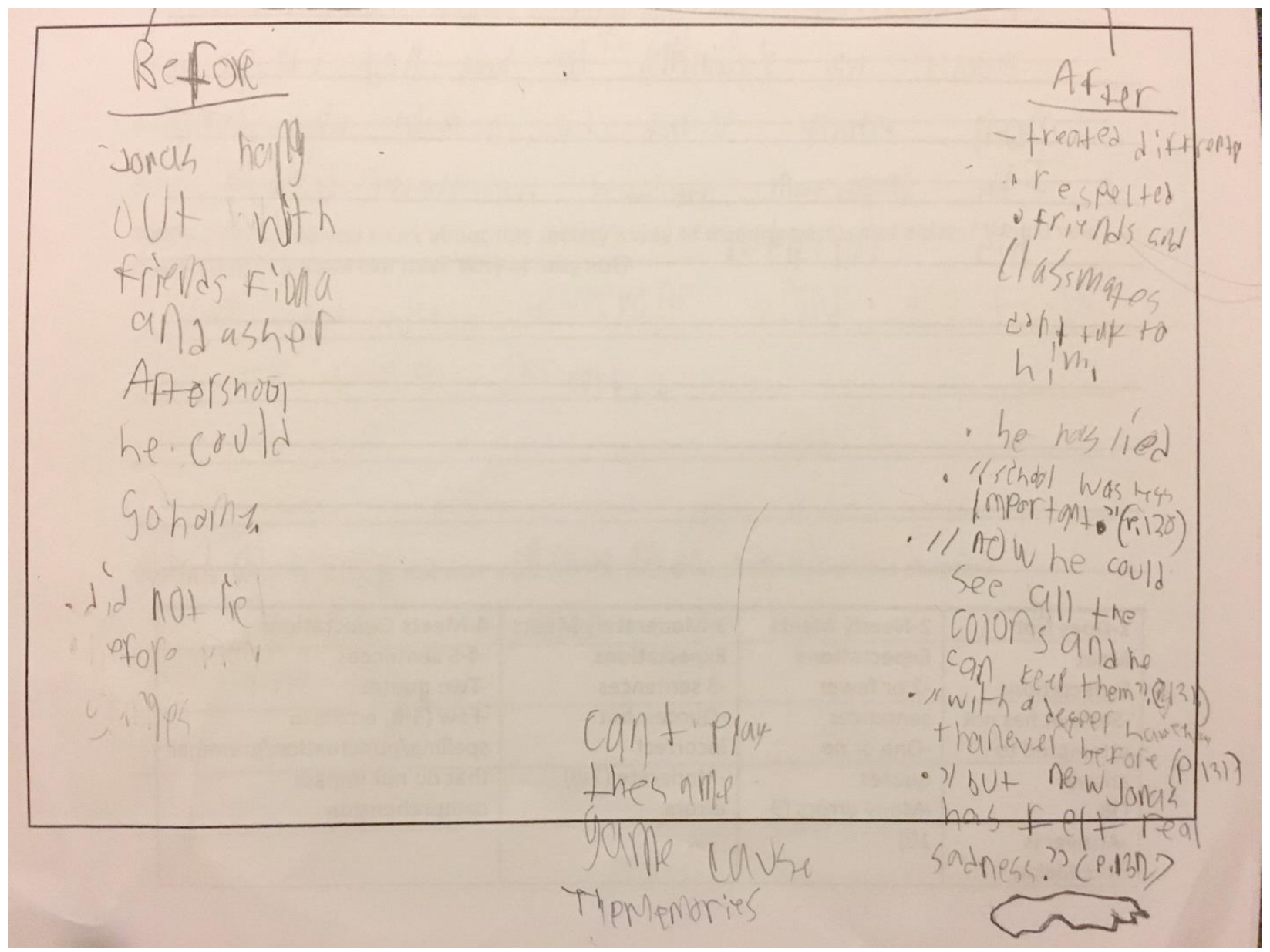

Figure 10. J. Cruz second semester increased work as a result of using breaks and thinking maps. 
EXIT TICKET: How has Jonas' life changed since becoming The Receiver of Memory? Write 4-5 complete sentences, include at least two pieces of evidence from the text (quotes).

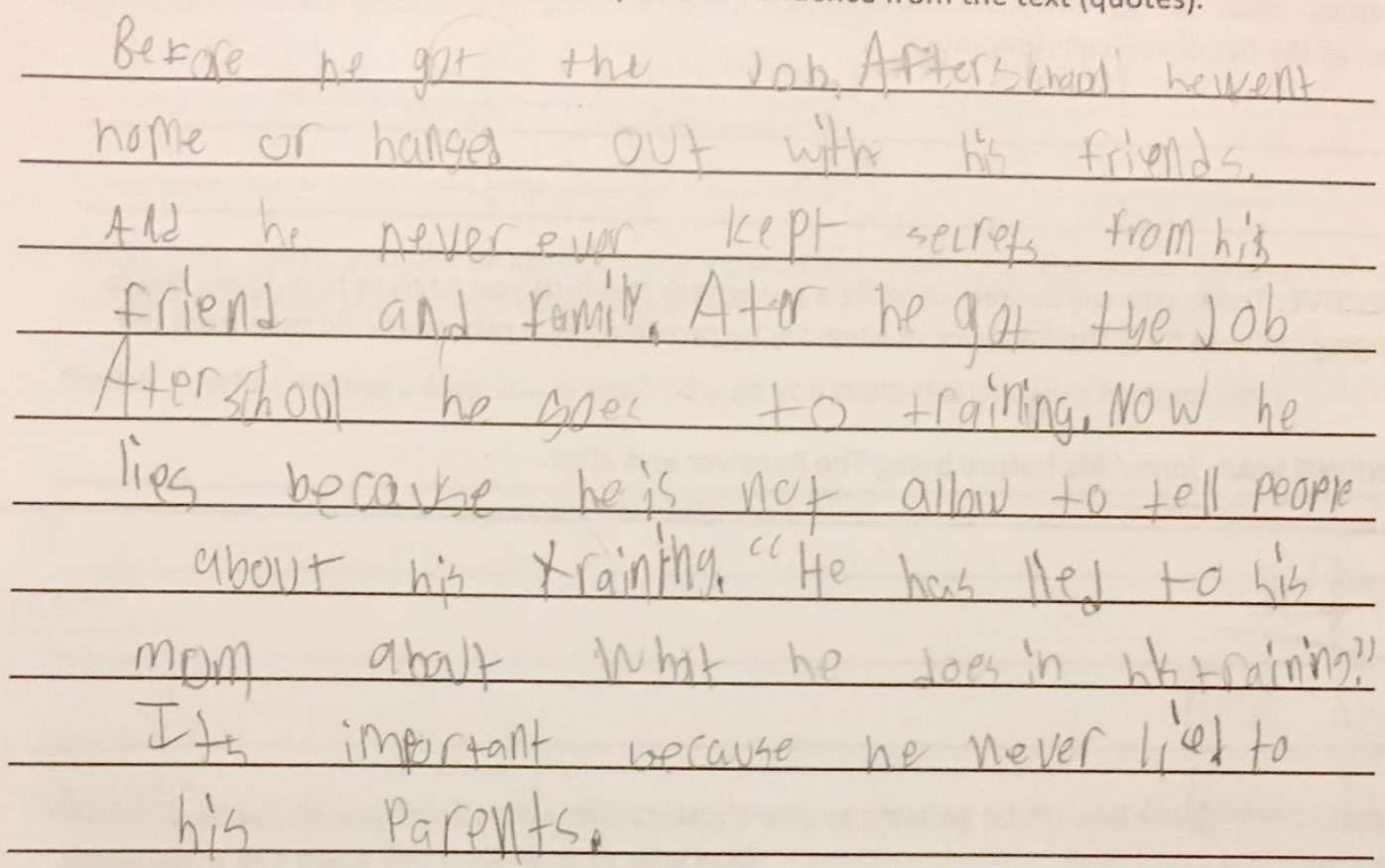

1-Does Not

Meet

Expectations

-Student has not

attempted to

answer

OR

-Answer is unreadable

2-Nearly Meets
Expectations
-2 or fewer
sentences
-One or no
quotes
-Many errors (9-
$10)$

3-Moderately Meets

Expectations

-3 sentences

-Quotes, but

incorrect

-Moderate (7-8)

errors

4-Meets Expectations

-4-5 sentences

-Two quotes

-Few (5-6) errors in

spelling/punctuation/grammar

that do not impact

comprehension

Figure 11. J. Cruz second semester work demonstrating improved focus and ability to complete work with breaks and encouragement. 
Appendix B

RI

First

Date:

Score:

Proficiency/Placement:

Last

Date:

Score:

Proficiency/Placement:

Highest

Date:

Score:

Proficiency/Placement:
$08 / 13 / 2018$

653

BB

03/14/2019

561

BB

08/13/2018

653

BB
iReady

$08 / 21 / 2018$

436

2 or More Levels Below

02/22/2019

445

2 or More Levels Below

$02 / 22 / 2019$

445

2 or More Levels Below

Figure 1. Y. Rivas RI scores beginning of the year and midyear show a decline in vocabulary proficiency. 


\begin{tabular}{|c|c|c|c|c|}
\hline & $\begin{array}{l}\text { GD World History } 7 \text { U5 2018- } \\
2019\end{array}$ & $\begin{array}{l}\text { GD ELA } 7 \text { Q1 Test 2018- } \\
\qquad 19\end{array}$ & $\begin{array}{l}\text { GD ELA } 7 \text { Q2 Test 2018- } \\
19\end{array}$ & $\begin{array}{c}\text { GD ELA } 7 \text { Q3 Test } 2018- \\
19\end{array}$ \\
\hline & 2018-2019 & August 2018 & August 2018 & August 2018 \\
\hline & $\%$ & $\%$ & $\%$ & $\%$ \\
\hline Total & 50 & 20.83 & 39.13 & 53.85 \\
\hline Reading: Literature & & 37.5 & 50 & 44.44 \\
\hline $\begin{array}{l}\text { Reading: Informational } \\
\text { Text }\end{array}$ & & 22.22 & 50 & 66.67 \\
\hline Writing & & 16.67 & 33.33 & 44.44 \\
\hline Language & & 0 & 0 & 66.67 \\
\hline Writing HST & & & & \\
\hline
\end{tabular}

Figure 2. D. Sanchez standardized benchmark test growth in ELA showing growth in all areas, particularly informational text. 


\begin{tabular}{|c|c|c|}
\hline & GD ELA 7 Q1 Test 2018-19 & GD ELA 7 Q2 Test 2018-19 \\
\hline & August 2018 & August 2018 \\
\hline & $\%$ & $\%$ \\
\hline Total & 16.67 & 26.09 \\
\hline Reading: Literature & 0 & 33.33 \\
\hline Reading: Informational Text & 11.11 & 40 \\
\hline Writing & 50 & 0 \\
\hline Language & 0 & 0 \\
\hline
\end{tabular}

Figure 3. J. Cruz standardized benchmark test growth in ELA showing overall growth and in particular growth in informational text comprehension. 